\title{
MODELLING DAILY EVAPOTRANSPIRATION USING ARTIFICIAL NEURAL NETWORKS UNDER HYPER ARID CONDITIONS
}

\author{
Mohamed A Yassin ${ }^{1, *}$, A A Alazba ${ }^{1,2}$ and Mohamed A. Mattar ${ }^{2,3}$ \\ ${ }^{1}$ Alamoudi Water Chair, King Saud University, P.O. Box 2460, Riyadh 11451, Saudi Arabia; ${ }^{2}$ Agricultural \\ Engineering Department, College of Food and Agriculture Sciences, King Saud University, P.O. Box 2460, Riyadh \\ 11451, Saudi Arabia; ${ }^{3}$ Agricultural Engineering Research Institute (AEnRI), P.O. Box 256, Giza, Egypt. \\ "Corresponding author's e-mail: myassin1@ksu.edu.sa
}

\begin{abstract}
Precisely determined evapotranspiration (ET) is necessary for maximization of water beneficiary use and hydrologic applications, particularly in arid and semiarid regions where water source is so limited, such as Saudi Arabia. Evapotranspiration is a complex, nonlinear process. However, data driven techniques can be used model it without requiring a complete understanding of the physics involved. Therefore, the Artificial Neural Networks (ANN) technique was used to estimate the daily reference evapotranspiration $\left(\mathrm{ET}_{\text {ref }}\right)$. Eight combinations of eight climatic parameters and crop height were used as input. The daily climatic variables were collected by 13 meteorological stations from 1980 to 2010. The ANN models were trained on $65 \%$ of the climatic data and tested using the remaining 35\%. The generalised Penman-Monteith (PMG) model was used as a reference target for evapotranspiration values, with $h_{c}$ varies from 5 to $105 \mathrm{~cm}$ with increment of a centimeter. The developed models were spatially validated using climatic data from 1980 to 2010 taken from another six meteorological stations. The results showed that the eight $\mathrm{ET}_{\text {ref }}$ models developed using the $\mathrm{ANN}$ technique to estimate $\mathrm{ET}_{\text {ref }}$ varies in significance depending on the climatic variables included. The more input climatic parameters included, the more accurate the ANN model is. The statistical performance criteria values such as determination coefficients $\left(\mathrm{R}^{2}\right)$ ranged from as low as $67.6 \%$ for ANN-MOD1, where air temperature is the only climatic parameter included, to as high as $99.8 \%$ for ANN-MOD8 with which all climatic parameters included. Furthermore, an interesting founded result is that the solar radiation has almost no effect on $\mathrm{ET}_{\text {ref }}$ under the hyper arid conditions. In contrast, the wind speed and plant height have a great positive impact in increasing the accuracy of calculating the daily reference evapotranspiration.
\end{abstract}

Keywords: Reference evapotranspiration, artificial neural network, Penman-Monteith model, alfalfa, grass, hyper arid.

\section{INTRODUCTION}

Water is the most important resource on the surface of the earth. Wherever water exists, life can be found. It is our duty to preserve, maintain and conserve this important resource. The water allocation to irrigated agriculture has recently decreased in arid and semi-arid regions where water is scarce. The Kingdom of Saudi Arabia (KSA) has limited water resources. Its geographical and astronomical features result in a warm, dry climate with little rainfall. Under the circumstances described, improvements to agricultural irrigation management and scheduling can greatly contribute to water conservation and the maintenance of sufficient levels of crop productivity and quality. Irrigation scheduling aims to replenish crop water requirements as quantified in evapotranspiration (ET) amounts (Ali, 2010). ET can be divided into the sub-processes evaporation and transpiration. Water passes into the atmosphere by evaporation from soil surfaces and by transpiration from plants (Allen et al., 1998; Fangmeier et al., 2006). ET can be determined either experimentally (directly) or mathematically (indirectly). It can be measured directly by using either a lysimeter or a water balance in a controlled crop area (Gavilan et al., 2007). However, this approach is difficult, time-consuming and expensive. Evapotranspiration can be calculated indirectly using a crop coefficient $\left(\mathrm{K}_{\mathrm{c}}\right)$ as determined by the crop type, stage of growth, canopy cover and density and soil moisture, multiplied by a reference evapotranspiration $\left(\mathrm{ET}_{\mathrm{ref}}\right)$ value (Allen et al., 1998).

An accurate estimate of the $\mathrm{ET}_{\text {ref }}$ is crucial for studies on the hydrologic water balance, irrigation system design and management, crop production, water resources planning and management and environmental assessment (Irmak et al., 2003; Temesgen et al., 2005; Chattopadhyay et al., 2009; Kumar et al., 2011). The $\mathrm{ET}_{\text {ref }}$ is affected by the daily temperature, relative humidity, wind velocity, sunshine hours, atmospheric pressure, amount of matter dissolved in the water and the latitude. The $\mathrm{ET}_{\text {ref }}$ can be calculated by several methods that use climatological data and empirical relationships based on temperature, radiation, mass transfer or a combination which based on physical processes.

Monteith (1965) introduced a surface conductance term to account for the response of leaf stomata to their hydrological environment. This modified form of the Penman equation is 
widely known as the General Penman-Monteith (PMG) evapotranspiration model (Monteith, 1973). This model is used by the United Nations' FAO (PMFAO) (Allen et al., 1998) and ASCE-70 (Jensen et al., 1990; Walter et al., 2001; ASCE, 2005) as the most accurate method for calculating the $\mathrm{ET}_{\text {ref }}$ and to validate other equations. It incorporates thermodynamic and aerodynamic aspects, can be applied to a wide range of climatic contexts (Smith et al., 1991; Yin et al., 2008) and requires many climatic data inputs. This is especially true in developing countries, which have limited reliable climatic data sets of radiation, relative humidity and wind speed (Gocic and Trajkovic, 2010; Tabari and Talaee, 2011).

Many studies have examined how other $\mathrm{ET}_{\text {ref }}$ equations with fewer data requirements perform against the PMG equation, to find alternative equations in the absence of some climatic data (e.g., George et al., 2002; Xu and Singh, 2002; Fooladmand et al., 2008; Sabziparvar and Tabari, 2010; Tabari, 2010). Temperature-based models, which are such as Hargreaves-Samani, Blaney-Criddle, and Thornthwaite, are some of the oldest methods for estimating the $\mathrm{ET}_{\text {ref }}(\mathrm{Xu}$ and Singh, 2001). Radiation-based models, which are such as Priestley-Taylor, Jensen-Haise, Makkink, and Turc, have been widely used to estimate evapotranspiration from land areas (Xu and Singh, 2001), which is based on the energy balance (Jensen et al., 1990). These models require calibration before extrapolating them to another environment (Kişi, 2006; Fooladmand and Haghighat, 2007).

Over the past decade, intelligent computational models have been developed as alternative methods for estimating the $\mathrm{ET}_{\text {ref }}$, such as the artificial neural network (ANN) technique (Gorka et al., 2008). ANNs are effective tools for modeling nonlinear processes, as they require few inputs and are able to map input-output relationships without any understanding of the physical process involved (Haykin, 1999; Sudheer et al., 2003). Several studies have used ANN to estimate the $\mathrm{ET}_{\text {ref }}$ as a function of climatic variables. Kumar et al. (2002) indicated that their ANN model predicted the $\mathrm{ET}_{\text {ref }}$ better than the PMFAO method. Kumar et al. (2008) developed ANN models based on different categories of conventional $\mathrm{ET}_{\text {ref }}$ estimation methods, the temperature-based, radiation-based and combination models (PMFAO). All of the ANN models performed better than their respective conventional methods in estimating the PMFAO $\mathrm{ET}_{\text {ref. }}$ Landeras et al. (2008) compared seven ANN models with different input combinations with ten locally calibrated empirical and semiempirical $\mathrm{ET}_{\text {ref }}$ models, using PMFAO daily $\mathrm{ET}_{\text {ref }}$ values as a reference. The results showed the ANN models obtained better results than the locally calibrated $\mathrm{ET}_{\text {ref }}$ equations. Huo et al. (2012) trained and tested ANN models to forecast the $\mathrm{ET}_{\text {ref }}$ using 50 years of climatic data from three stations in north-west China. They showed that the ANN models exhibited high precision compared to the other models Our incomplete understanding of the physical evapotranspiration process and a lack of the relevant data results in inaccurate $\mathrm{ET}_{\text {ref }}$ estimates. Simple, direct approaches with limited data requirements are needed. The objectives of this study are to: (1) Develop daily $\mathrm{ET}_{\text {ref }}$ models using the ANN technique from limited variables, (3) Spatially assess the developed daily $\mathrm{ET}_{\text {ref }}$ models, and (2) Assess the accuracy of the developed ANN models with PMFAO and PMASCE models.

\section{MATERIALS AND METHODS}

Study area and climatic data: The KSA is situated in the far southwest corner of Asia (Fig. 1), between latitudes $16^{\circ} 22^{\prime} 46^{\prime \prime} \mathrm{N}$ and $32^{\circ} 14^{\prime} 00^{\prime \prime} \mathrm{N}$ and longitudes $34^{\circ} 29^{\prime} 30^{\prime \prime} \mathrm{E}$ and $55^{\circ} 40^{\prime} 00^{\prime \prime} \mathrm{E}$. It is the largest country in Arabia. The KSA occupies about $70 \%$ of the area of the Arabian Peninsula with an approximate area of $1,950,000 \mathrm{~km}^{2}$. It is divided into thirteen provinces, as shown in Figure 1. This study considers all of the provinces. The provinces are arranged by area in descending order in Table 1. The KSA's climate varies from region to region, depending on the terrain. The climate is generally characterized by hot summers, cold winters and winter rainfall. The central areas experience hot, dry summers and cool, dry winters. The coastal areas experience high humidity. The air temperature falls moderately with the onset of autumn, which lasts from 23 September to 21 December. The lowest air temperatures are reported in the northern regions $\left(3-7^{\circ} \mathrm{C}\right)$. Later in the year, temperatures significantly decline in other areas. Temperature variations are noted daily and vary from region to region.

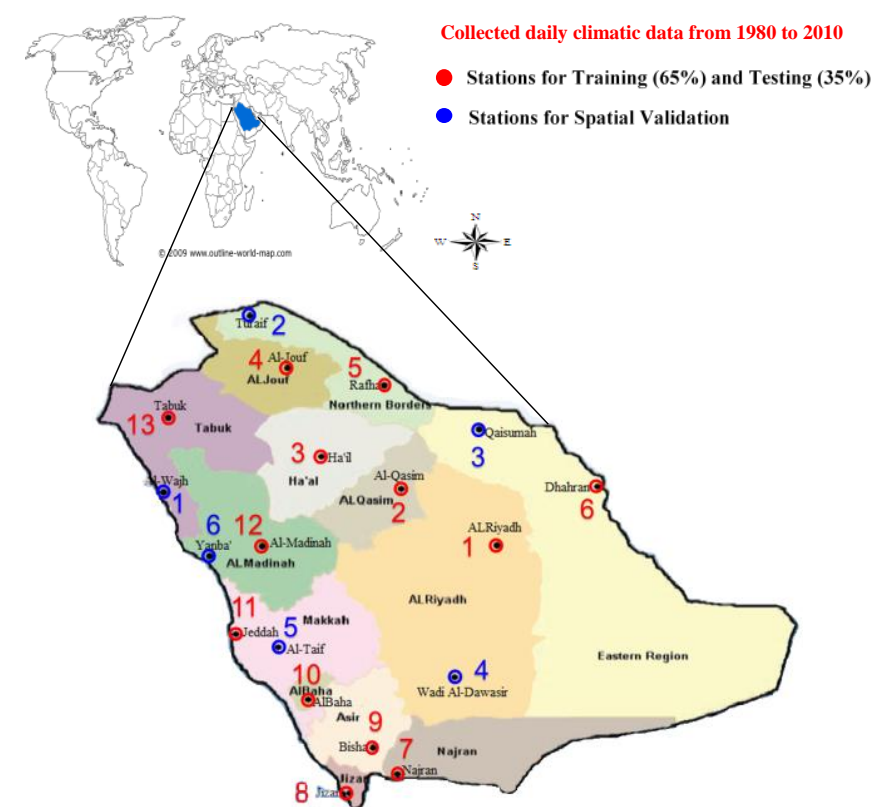

Figure 1. Map of the KSA, showing its provinces and meteorological stations. 
Table 1. Meteorological station sites and climatic parameters.

\begin{tabular}{|c|c|c|c|c|c|c|c|c|c|c|c|c|c|}
\hline \multirow[t]{2}{*}{ Provinces } & \multirow{2}{*}{$\begin{array}{c}\operatorname{Areas}^{*} \\
\left(\mathbf{k m}^{2}\right)\end{array}$} & \multirow[t]{2}{*}{ Stations } & \multicolumn{3}{|c|}{ Location } & \multicolumn{8}{|c|}{ Climatic Parameters } \\
\hline & & & $\begin{array}{c}\begin{array}{c}\text { Longitude } \\
\text { (deg) }\end{array} \\
\text { (deg }\end{array}$ & $\begin{array}{c}\text { Latitude } \\
\text { (deg) }\end{array}$ & $\begin{array}{l}\text { Altitude } \\
\text { (m) }\end{array}$ & $\begin{array}{c}\mathbf{T}_{\mathbf{x}} \\
\left({ }^{\circ} \mathbf{C}\right)\end{array}$ & $\begin{array}{c}\mathbf{T}_{\mathbf{n}} \\
\left({ }^{\circ} \mathbf{C}\right)\end{array}$ & $\begin{array}{c}\mathbf{T}_{\mathbf{a}} \\
\left({ }^{\circ} \mathbf{C}\right)\end{array}$ & $\begin{array}{l}\mathbf{R h}_{\mathbf{x}} \\
(\%)\end{array}$ & $\begin{array}{l}\mathbf{R h}_{\mathbf{n}} \\
(\%)\end{array}$ & $\begin{array}{l}\mathbf{R h}_{\mathbf{a}} \\
(\%)\end{array}$ & $\begin{array}{c}\mathrm{U}_{2} \\
(\mathrm{~m} / \mathrm{s})\end{array}$ & $\begin{array}{c}\mathbf{R}_{\mathrm{s}} \\
\left(\mathrm{Mj} / \mathbf{m}^{2} / \mathbf{d}\right)\end{array}$ \\
\hline \multirow{2}{*}{$\begin{array}{l}\text { Eastern } \\
\text { region }\end{array}$} & \multirow[t]{2}{*}{540} & Qaisumah & 46.13 & 28.31 & 355 & 32 & 19 & 25 & 77 & 30 & 50 & 2.6 & 21 \\
\hline & & Dhahran & 50.20 & 26.30 & 17 & 33 & 20 & 26 & 75 & 29 & 52 & 4.2 & 20 \\
\hline \multirow[t]{2}{*}{ Al-Riyadh } & \multirow[t]{2}{*}{380} & Riyadh (North) & 46.72 & 24.93 & 614 & 33 & 20 & 26 & 38 & 16 & 31 & 3.9 & 15 \\
\hline & & Wadi Al-Dawasir & 45.20 & 20.50 & 617 & 35 & 22 & 28 & 35 & 17 & 26 & 3.4 & 18 \\
\hline \multirow[t]{2}{*}{ Al-Madinah } & \multirow[t]{2}{*}{150} & Al-Madina & 39.60 & 24.47 & 619 & 33 & 25 & 19 & 56 & 29 & 44 & 4.2 & 26 \\
\hline & & Yanba' & 38.10 & 24.10 & 1 & 29 & 22 & 17 & 78 & 23 & 50 & 3.2 & 29 \\
\hline \multirow[t]{2}{*}{ Makkah } & \multirow[t]{2}{*}{137} & Jeddah & 39.17 & 21.40 & 12 & 34 & 28 & 22 & 81 & 37 & 60 & 2.6 & 23 \\
\hline & & Al-Ta'if & 40.50 & 21.50 & 1449 & 35 & 29 & 23 & 60 & 29 & 39 & 3.2 & 27 \\
\hline \multirow[t]{2}{*}{ Tabuk } & \multirow[t]{2}{*}{136} & Tabuk & 36.58 & 28.38 & 770 & 29 & 14 & 22 & 53 & 17 & 32 & 2.9 & 33 \\
\hline & & Al-Wajh & 36.50 & 26.20 & 20 & 28 & 10 & 18 & 70 & 22 & 45 & 2.2 & 29 \\
\hline Najran & 130 & Najran & 44.40 & 17.60 & 1214 & 35 & 29 & 25 & 60 & 33 & 44 & 3.5 & 28 \\
\hline Ha'Il & 120 & Ha'il & 41.70 & 27.40 & 1013 & 34 & 28 & 22 & 81 & 37 & 60 & 2.3 & 14 \\
\hline Northern & 104 & Turaif & 38.65 & 31.68 & 854 & 35 & 29 & 23 & 60 & 29 & 39 & 3.3 & 29 \\
\hline borders & & Rafha & 43.50 & 29.60 & 447 & 29 & 14 & 22 & 53 & 17 & 32 & 2.9 & 22 \\
\hline Al-Jouf & 85 & Al-Jouf & 40.10 & 29.80 & 689 & 30 & 14 & 22 & 48 & 18 & 31 & 3.11 & 25 \\
\hline Asir & 80 & Bisha & 42.60 & 20.00 & 1157 & 33 & 17 & 25 & 47 & 15 & 29 & 2.4 & 28 \\
\hline Al-Qasim & 73 & Al-Qasim & 43.80 & 26.30 & 650 & 32 & 18 & 25 & 44 & 30 & 18 & 2.9 & 27 \\
\hline Jizan & 13 & Jizan & 42.60 & 16.88 & 3 & 36 & 30 & 25 & 61 & 34 & 44 & 3.3 & 36 \\
\hline Al-Bahah & 12 & Al-Baha & 41.60 & 20.30 & 1656 & 29 & 16 & 22 & 56 & 22 & 38 & 1.3 & 28 \\
\hline
\end{tabular}

* Saudi Geological Survey (2012), King Saudi Arabia: Facts and Numbers, edition 1

For this study, climatic data was recorded at 19 meteorological stations selected from the 13 KAS provinces. The spatial distribution of the selected stations within the provinces is shown in Figure 1. Each province is represented by two stations, except for the provinces of Najran, Ha'il, AlJouf, Bisha, Al-Qasim, Jizan and Al-Baha, which are only represented by one station. The Presidency of Meteorology and Environment provided the data. The study's climatic data covers 31 years of daily meteorological information recorded from 1980 to 2010. The recorded data for all of the stations includes the maximum, minimum and mean air temperatures $\left(\mathrm{T}_{\mathrm{x}}, \mathrm{T}_{\mathrm{n}}\right.$, and $\left.\mathrm{T}_{\mathrm{a}}\right)\left({ }^{\circ} \mathrm{C}\right)$; maximum, minimum and mean relative humidity $\left(\mathrm{Rh}_{\mathrm{x}}, \mathrm{Rh}_{\mathrm{n}}\right.$ and $\left.\mathrm{Rh}_{\mathrm{a}}\right)(\%)$; wind speed at a $2 \mathrm{~m}$ height $\left(\mathrm{U}_{2}\right)(\mathrm{m} / \mathrm{s})$ and solar radiation $\left(\mathrm{R}_{\mathrm{s}}\right)\left(\mathrm{Mj} / \mathrm{m}^{2} / \mathrm{d}\right)$. Table 1 describes the meteorological stations and lists the annual averages of the climatic data from each station.

The ANN models take at most nine input variables, $T_{x}, T_{n}, T_{a}$, $\mathrm{Rh}_{\mathrm{x}}, \mathrm{Rh}_{\mathrm{n}}, \mathrm{Rh}_{\mathrm{a}}, \mathrm{U}_{2}, \mathrm{R}_{\mathrm{s}}$ and the reference crop height $\left(\mathrm{h}_{\mathrm{c}}\right)(\mathrm{m})$, which varies from 5 to $105 \mathrm{~cm}$. This range is selected to cover both grass $(10$ to $15 \mathrm{~cm})$ and alfalfa $(30$ to $80 \mathrm{~cm})$. A random $\mathrm{h}_{\mathrm{c}}$ value is chosen during training. The $\mathrm{ET}_{\mathrm{ref}}$ is the output variable. The input variables are divided into three sets. The training set for the ANN models is composed of $65 \%$ of the daily data collected by 13 of the weather stations, Riyadh (North), Al-Qasim, Ha'il, Al-Jouf, Rafha, Dhahran, Najran, Jizan, Bisha, Al-Baha, Jeddah, Al-Madina and Tabuk, from 1980 to 2007. The training set is used to find the patterns present in the data. The testing set for the ANN models is composed of the remaining $35 \%$ of the data from the same weather stations and period as the training set. It is used to evaluate the generalization abilities of the trained models. The
ANN models' performances are checked once more with a validation data set. It is composed of the data collected by the remaining six weather stations, Turaif, Al-Wajh, Qaisumah, Yanba', Al-Ta'if and Wadi Al-Dawasir, from 1980 to 2010. The data is analyzed three times, using $h_{c}=5-105 \mathrm{~cm}, h_{c}=12$ $\mathrm{cm}$ and $\mathrm{h}_{\mathrm{c}}=50 \mathrm{~cm}$.

Input parameters data of the ANN models: The ANN models take at most nine input variables, maximum, minimum and mean air temperature $\left(\mathrm{T}_{\mathrm{x}}, \mathrm{T}_{\mathrm{n}}\right.$ and $\left.\mathrm{T}_{\mathrm{a}}\right)$; maximum, minimum and mean relative humidity $\left(\mathrm{Rh}_{\mathrm{x}}, \mathrm{Rh}_{\mathrm{n}}\right.$ and $\left.\mathrm{Rh} \mathrm{h}_{\mathrm{a}}\right)$; wind speed $\left(U_{2}\right)$; solar radiation $\left(R_{s}\right)$ and the reference crop height $\left(h_{c}\right)$, which varies from 5 to $105 \mathrm{~cm}$. This range is selected to cover both grass $(8$ to $15 \mathrm{~cm})$ and alfalfa $(30$ to $80 \mathrm{~cm})$. A random $\mathrm{h}_{\mathrm{c}}$ value is chosen during training. The $\mathrm{ET}_{\text {ref }}$ is the output variable. The input variables are divided into three sets. The training set for the ANN models is composed of $65 \%$ of the daily data collected by 13 of the meteorological stations, Riyadh (North), Al-Qasim, Ha'il, Al-Jouf, Rafha, Dhahran, Najran, Jizan, Bisha, Al-Baha, Jeddah, Al-Madina and Tabuk, from 1980 to 2010. The training set is used to find the patterns present in the data. The testing set for the ANN models is composed of the remaining $35 \%$ of the data from the same meteorological stations and period as the training set. It is used to evaluate the generalization abilities of the trained models.

The ANN models' performances are checked once more with a validation data set. It is composed of the data collected by the remaining 6 meteorological stations, Turaif, Al-Wajh, Qaisumah, Yanba', Al-Ta'if and Wadi Al-Dawasir, from 1980 to 2010.The data is analysed three times, using hc=5$105 \mathrm{~cm}, \mathrm{hc}=12 \mathrm{~cm}$ and $\mathrm{hc}=50 \mathrm{~cm}$. 
Table 2. The input variables combinations used in the ANN technique.

\begin{tabular}{|c|c|c|c|c|c|c|c|c|c|}
\hline \multirow[t]{3}{*}{ Model } & \multicolumn{9}{|c|}{ Input Parameters } \\
\hline & \multicolumn{3}{|c|}{ Temperature $\left({ }^{\circ} \mathbf{C}\right)$} & \multicolumn{3}{|c|}{ Relative Humidity (\%) } & \multirow{2}{*}{$\begin{array}{c}\mathbf{u}_{2} \\
(\mathbf{m} / \mathbf{s})\end{array}$} & \multirow{2}{*}{$\begin{array}{c}\mathbf{R}_{\mathrm{s}} \\
\left(\mathrm{Mj} / \mathbf{m}^{2} / \mathbf{d}\right)\end{array}$} & \multirow{2}{*}{$\begin{array}{c}\mathbf{h}_{\mathbf{c}} \\
(\mathbf{m})\end{array}$} \\
\hline & $\mathbf{T}_{\mathbf{x}}$ & $\mathbf{T}_{\mathbf{n}}$ & $\mathbf{T}_{\mathbf{a}}$ & $\mathbf{R h}_{\mathbf{x}}$ & $\mathbf{R h}_{\mathbf{n}}$ & $\mathbf{R h}_{\mathbf{a}}$ & & & \\
\hline$\overline{\text { ANN-MOD1 }}$ & $\checkmark$ & $\checkmark$ & $\checkmark$ & & & & & & $\checkmark$ \\
\hline ANN-MOD2 & $\checkmark$ & $\checkmark$ & $\checkmark$ & $\checkmark$ & $\checkmark$ & $\checkmark$ & & & $\checkmark$ \\
\hline ANN-MOD3 & $\checkmark$ & $\checkmark$ & $\checkmark$ & & & & $\checkmark$ & & $\checkmark$ \\
\hline ANN-MOD4 & $\checkmark$ & $\checkmark$ & $\checkmark$ & & & & & $\checkmark$ & $\checkmark$ \\
\hline ANN-MOD5 & $\checkmark$ & $\checkmark$ & $\checkmark$ & $\checkmark$ & $\checkmark$ & $\checkmark$ & $\checkmark$ & & $\checkmark$ \\
\hline ANN-MOD6 & $\checkmark$ & $\checkmark$ & $\checkmark$ & $\checkmark$ & $\checkmark$ & $\checkmark$ & & $\checkmark$ & $\checkmark$ \\
\hline ANN-MOD7 & $\checkmark$ & $\checkmark$ & $\checkmark$ & & & & $\checkmark$ & $\checkmark$ & $\checkmark$ \\
\hline ANN-MOD8 & $\checkmark$ & $\checkmark$ & $\checkmark$ & $\checkmark$ & $\checkmark$ & $\checkmark$ & $\checkmark$ & $\checkmark$ & $\checkmark$ \\
\hline
\end{tabular}

The input combinations: Several combinations of the input parameters were used as inputs to estimate the daily $\mathrm{ET}_{\text {ref }}$ using the ANN technique. The input parameter combinations are listed in Table 2. Eight ANN models were developed to test the performance of different combinations of input parameters, including climatic parameters and a reference $h_{c}$ chosen randomly during the training process. The three temperature variables $\left(\mathrm{T}_{\mathrm{x}}, \mathrm{T}_{\mathrm{n}}\right.$, and $\left.\mathrm{T}_{\mathrm{a}}\right)$ and $\mathrm{h}_{\mathrm{c}}$ were included in all of the combinations.

The first combination used the three temperature elements and crop height. The second combination added the three humidity variables $\left(\mathrm{Rh}_{\mathrm{x}}, \mathrm{Rh}_{\mathrm{n}}\right.$, and $\left.\mathrm{Rh}_{\mathrm{a}}\right)$ to the first combination. The third combination added $\mathrm{U}_{2}$ to the first combination. The fourth combination added $\mathrm{R}_{\mathrm{s}}$ to the first combination. The fifth combination was formed by inserting $\mathrm{u}_{2}$ into the second combination. The sixth combination was formed by inserting $R_{s}$ into the second combination. The seventh combination consisted of all inputs parameters except the relative humidity data. The eighth combination consisted of all the input parameters.

Output/targeted data of the ANN models: The performances of the ANN models are compared to the PMG method. The PMG method is considered the standard procedure when measured lysimeter data is not available (Irmak et al., 2003; Gavilan et al., 2006). The PMG method gives optimal results over all climatic zones (De Souza and Yoder, 1994; Chiew et al., 1995; Hupet and Vanclooster, 2001; Naoum and Tsanis, 2003; Irmak et al., 2003; Alazba, 2004; Gavilan et al., 2006) and has advantages over many other mathematical equations. It can be used globally without any local calibrations due to its physical basis, is well-documented and has been validated with a significant amount of lysimeter data (Gocic and Trajkovic, 2010). Many researchers (Kumar et al., 2002; Trajkovic, 2005; Kisi and Ozturk, 2007; Zanetti et al., 2007; Landeras et al., 2008; Jain et al., 2008; Dai et al., 2009; Traore et al., 2010) have used the PMG equation as a reference and standard equation to evaluate the results of their mathematical models. The daily $\mathrm{ET}_{\text {ref }}$ values from the PMG equation are used as the output/target variables in the ANN and GEP models. A generalized form of the Penman-Monteith model can be written as (Alazba, 2004):

$$
E T_{r e f}=\lambda^{-1}\left[\frac{\Delta}{\Delta+\gamma^{*}}\left(R_{n}-G\right)+\frac{\gamma}{\Delta+\gamma^{*}} K\left(e_{s}-e_{a}\right)\right]
$$

Where

$\lambda=$ latent heat of vaporization, $\left(\mathrm{MJ} . \mathrm{kg}^{-1}\right)$;

$\Delta=$ slope of the saturation vapour pressure-temperature curve at the mean air temperature $\left(\mathrm{kPa} .{ }^{\circ} \mathrm{C}^{-1}\right)$;

$\gamma=$ psychometric constant $\left(\mathrm{kPa} .{ }^{\circ} \mathrm{C}^{-1}\right)$;

$\mathrm{R}_{\mathrm{n}}=$ net radiation $\left(\mathrm{MJ} \cdot \mathrm{m}^{-2} \mathrm{day}^{-1}\right)$;

$G=$ soil heat flux $\left(\mathrm{MJ} \cdot \mathrm{m}^{-2} \mathrm{day}^{-1}\right)$;

$\gamma^{*}=$ modified psychometric constant $\left(\mathrm{kPa} .{ }^{\circ} \mathrm{C}^{-1}\right)$;

$K=$ parameter equal to $1.854 \times 10^{5} \frac{\lambda / \mathrm{r}_{\mathrm{a}}}{\mathrm{T}+273}\left(\mathrm{MJ}^{-2} \mathrm{~m}^{-2}\right.$ day. $\left.\mathrm{kPa}\right)$

$r_{a}=$ aerodynamic resistance $\left(\mathrm{s} . \mathrm{m}^{-1}\right)$;

$T=$ air temperature $\left({ }^{\circ} \mathrm{C}\right)$;

$e_{s}=$ saturation vapour pressure at the air temperature (kPa); and

$\mathrm{e}_{\mathrm{a}}=$ actual vapour pressure $(\mathrm{kPa})$.

Description of artificial neural network ANN: ANN usually consists of layers of neurons, weights representing the connection strengths and a transfer or activation function. An ANN model of multilayer perception with a universal function approximator is used. Figure 2 depicts the model layers.

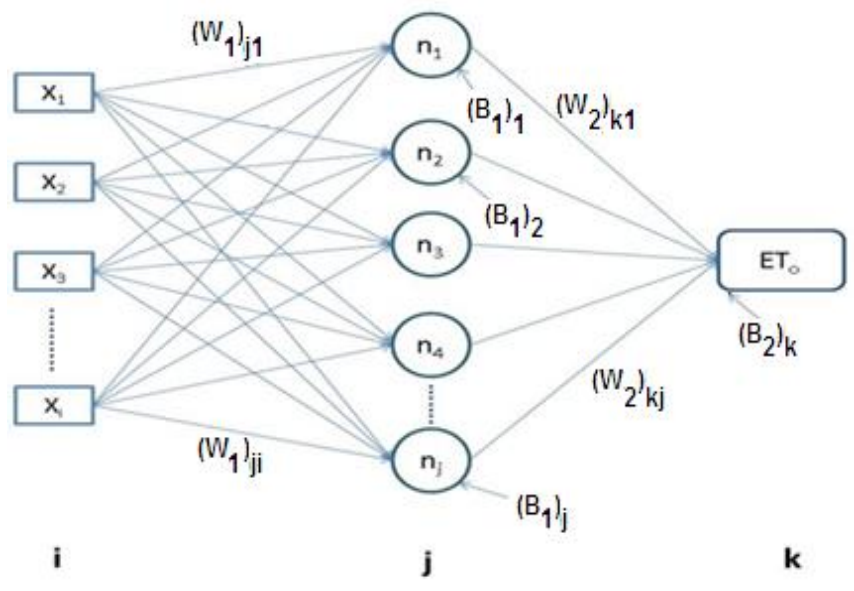

input layer

hidden layer

output layer

Figure 2. Architecture of the ANN used to model the ET ref. 
The input layer $(i)$ is connected to the hidden layer $(j)$, which is in turn connected to the output layer $(k)$ by means of the connection weights $(W)$ and biases $(B)$. The $W$ is used to change the throughput parameters and vary the connections to the neurons. The $B$ is used as additional elements inside the hidden and output layer neurons. The neuron (processing element) in the hidden layer consists of aggregating weighted inputs, resulting in a quantity-weighted input (activation value). In the hidden layer, the neuron's activation value $\left(h_{j}\right)$ is mathematically characterized using the following equation (Haykin 1999):

$$
h_{j}=f\left(\sum_{i=1}^{N}\left(W_{1}\right)_{j i} X_{i}+\left(B_{1}\right)_{j}\right)
$$

Where $\left(W_{l}\right)_{j i}$ is weights from the input layer to the hidden layer; $X_{i}$ is input parameters; $N$ is number of input neurons; $\left(B_{1}\right)_{j}$ is biases in the hidden layer; $f(--)$ is activation (transfer) function.

Then, the output layer neuron $\left(Y_{k}\right)$ is given by the following equation:

$$
Y_{k}=f\left(\sum_{j=1}^{n}\left(W_{2}\right)_{k j} h_{j}+\left(B_{2}\right)_{k}\right)
$$

Where $\left(W_{2}\right)_{k j}$ is weights from the hidden layer to the output layer; $n$ is number of output neurons; $\left(B_{2}\right)_{k}$ is biases in the output layer.

The most common activation (transfer) functions in hydrological modeling are the sigmoid and hyperbolic tangent functions (Dawson \& Wilby, 1998; Zanetti et al., 2007). The hyperbolic tangent is similar to the sigmoid but can exhibit different learning dynamics during training. The sigmoid function is used in this study. Its general functional form is:

$$
f(x)=\frac{1}{1+\exp (-x)}
$$

A feed-forward ANN that uses a back-propagation learning algorithm was employed in this study; as such ANNs are commonly used to estimate the $\mathrm{ET}_{\text {ref. }}$ The back-propagation learning algorithm optimizes the error function to modify the link weight. More than $70 \%$ of the existing studies that applied ANN techniques to hydrological processes used the back-propagation learning algorithm because of its simplicity and robustness (Kumar et al., 2011). It controls the rate at which learning takes place using a momentum term and the learning rate. The momentum term is generally used to accelerate convergence and avoid local minima. A learning rate of 0.01 and a momentum factor of 0.8 are used.

Developing the ANN architecture: Software Multiple BackPropagation version 2.2.4 was used to develop the ANN models to estimate the $\mathrm{ET}_{\text {ref. Nine input variables were used }}$ (the maximum input set of the ANN). The output as one neuron was in the output layer. The number of hidden neurons depended on several factors, such as the number of input and output neurons, the number of training cases, the amount of noise in the targets, the complexity of the function or classification to be learned, the architecture, the type of hidden unit activation function and the training algorithm (Kumar et al., 2011). The training data must be automatically normalized before they are exported to the ANN's feedforward neural networks for training. Normalization is commonly between 0.15 and 0.85 in ANN modeling. The input data can flow after it is normalized. They undergo unidirectional processing from the input layer, through the hidden layer, to the output layer. In the hidden layer, each neuron receives input signals from the input layer through the weights (Izadifar, 2010). The data are processed separately by each hidden layer neuron and the outputs are passed to the output layer neuron.

The network output and target outputs are computed at the end of each forward pass in the forward-propagation stage. If an error is higher than a selected value, a reverse pass is performed to modify the connection weights by minimizing the error between the target and computed outputs (backpropagation stage). Otherwise, the training stops. The best number of hidden neurons in the hidden layer is found by training many ANNs and repeating the trial and error procedure (Jain et al., 2008), taking into account the error values. The hidden layer initially has two nodes. The number of nodes increases in each trial by between one and four nodes, to a maximum of 20 nodes.

Performance criteria of ANN models: After training the ANN models, the $\mathrm{ET}_{\text {ref }}$ values were estimated and compared to the daily values from the PMG model. The comparisons were made using the following statistical parameters.

$$
\begin{aligned}
& R^{2}=\frac{\left(\sum_{i=1}^{n^{\prime}}\left(E_{i}-\bar{E}\right)\left(C_{i}-\bar{C}\right)\right)^{2}}{\sum_{i=1}^{n^{\prime}}\left(E_{i}-\bar{E}\right)^{2} \cdot \sum_{i=1}^{n^{\prime}}\left(C_{i}-\bar{C}\right)^{2}} \\
& R M S E=\sqrt{\frac{\sum_{i=1}^{n^{\prime}}\left(E_{i}-C_{i}\right)^{2}}{n^{\prime}}} \\
& O I=\frac{1}{2}\left(2-\frac{R M S E}{E_{x}-E_{n}}+\frac{\sum_{i-1}^{n^{\prime}}\left(E_{i}-C_{i}\right)^{2}}{\sum_{i=1}^{n^{\prime}}\left(E_{i}-\bar{E}\right)^{2}}\right) \\
& M A E=\frac{\sum_{i=1}^{n^{\prime}}\left|E_{i}-C_{i}\right|}{n^{\prime}}
\end{aligned}
$$

Where $E_{i}$ is value of $E T_{r e f}$ estimated by the PMG; $C_{i}$ is corresponding value calculated by mathematical $E T_{\text {ref }}$ models; $n$ ' is number of observations; $\bar{E}$ is average of the estimated values; $\bar{C}$ is average of the calculated values; $E_{x}$ is maximum estimated value; $E_{n}$ is minimum estimated value. 


\section{RESULTS AND DISCUSSION}

Choosing the ANN architecture: The optimal number of neurons in the hidden layers of an ANN must be determined through a trial and error procedure, as shown in Figure 2. Of

the eight ANNs tested, the simplified construct $N-2-1$ (where $N$ is the number of neurons or input variables in the input layer) exhibits the poorest ANN performance, as reflected by the statistical indicators (Figs. 3 and 4). High values of $R^{2}$ and $O I$ and low values of $R M S E$ and $M A E$, indicating good model
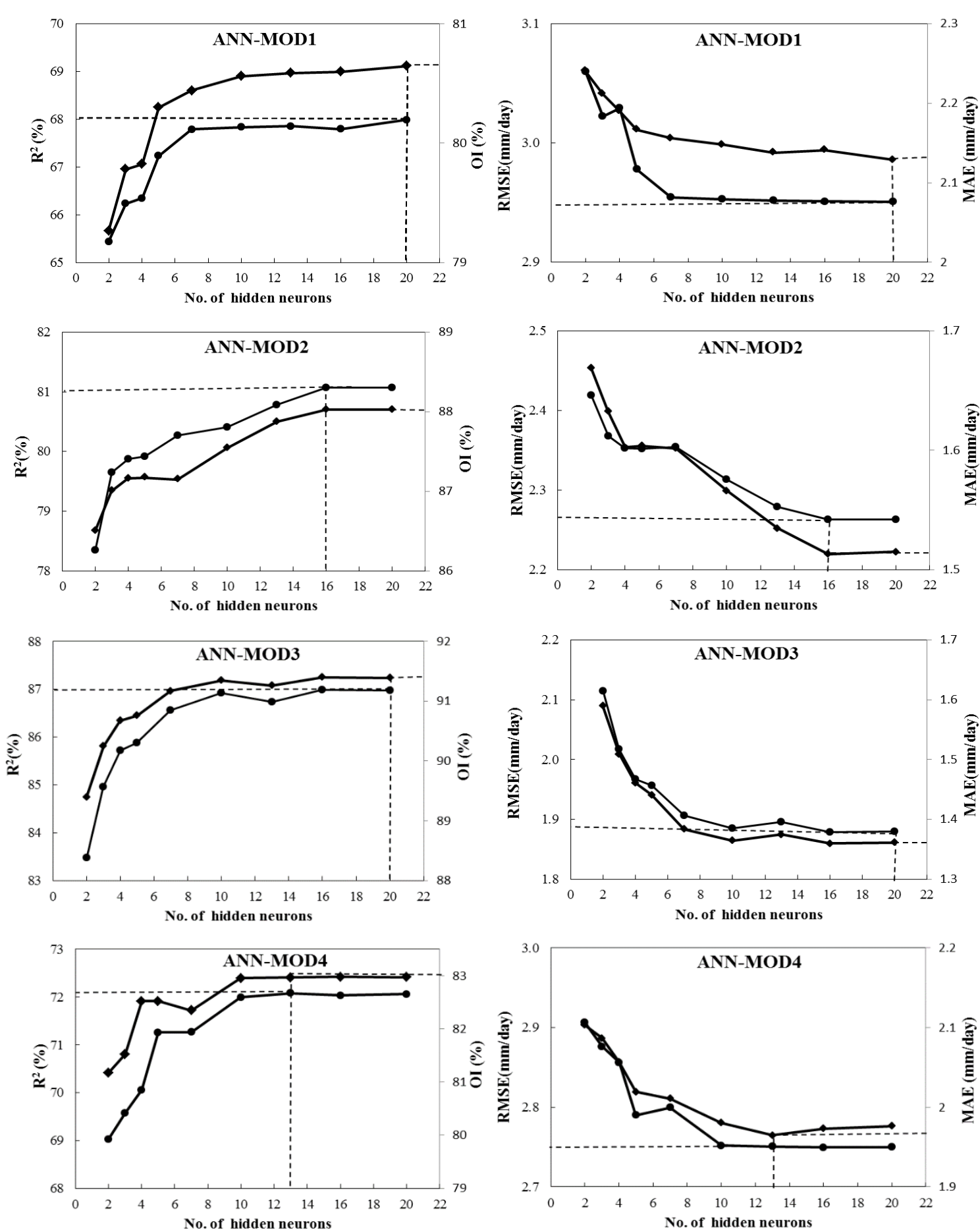

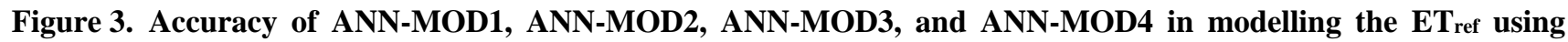
different numbers of hidden neurons during training, measured with $R^{2}, O I, R M S E$ and $M A E$. 
performance, are obtained by increasing $n$ (where $n$ is the number of neurons in the hidden layer) to more than two.

It can be noted that a greater number of neurons in the hidden layer increases the structure complexity and does not improve the network behaviour. The optimum number of hidden layers represents the $\mathrm{ET}_{\text {ref }}$ nonlinear complex relationship (Kumar et al., 2002; Zanetti et al., 2007). The numbers of neurons in the
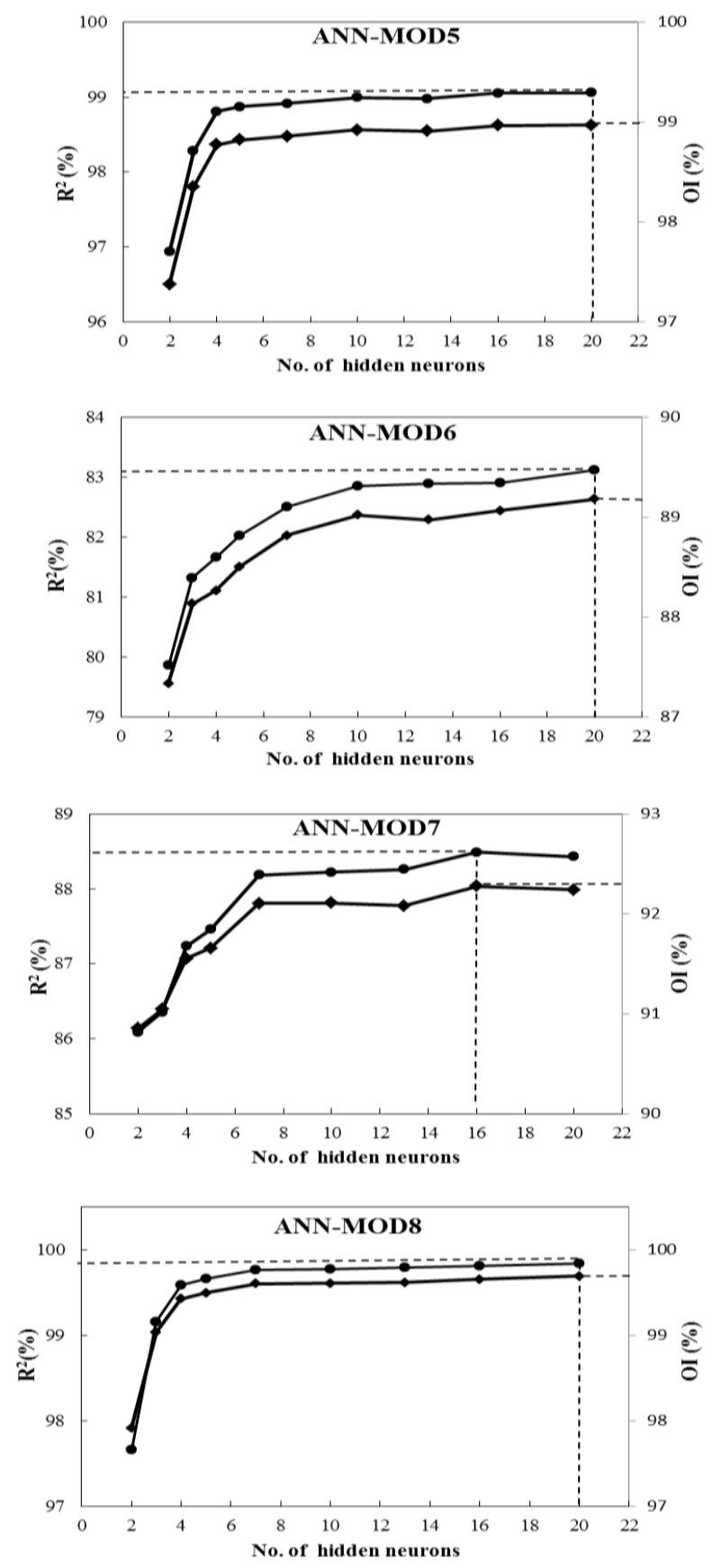

hidden layer of the ANN models used for the various training models were $2,3,4, \ldots . ., 20$. The networks were trained over up to 20,000 iterations, as there were negligible improvements (increases in the $R^{2}$ and decreases in the RMSE) after 20,000 iterations.

For example, ANN-MOD1 was trained using up to 20 processing elements. The optimum results are found using 20
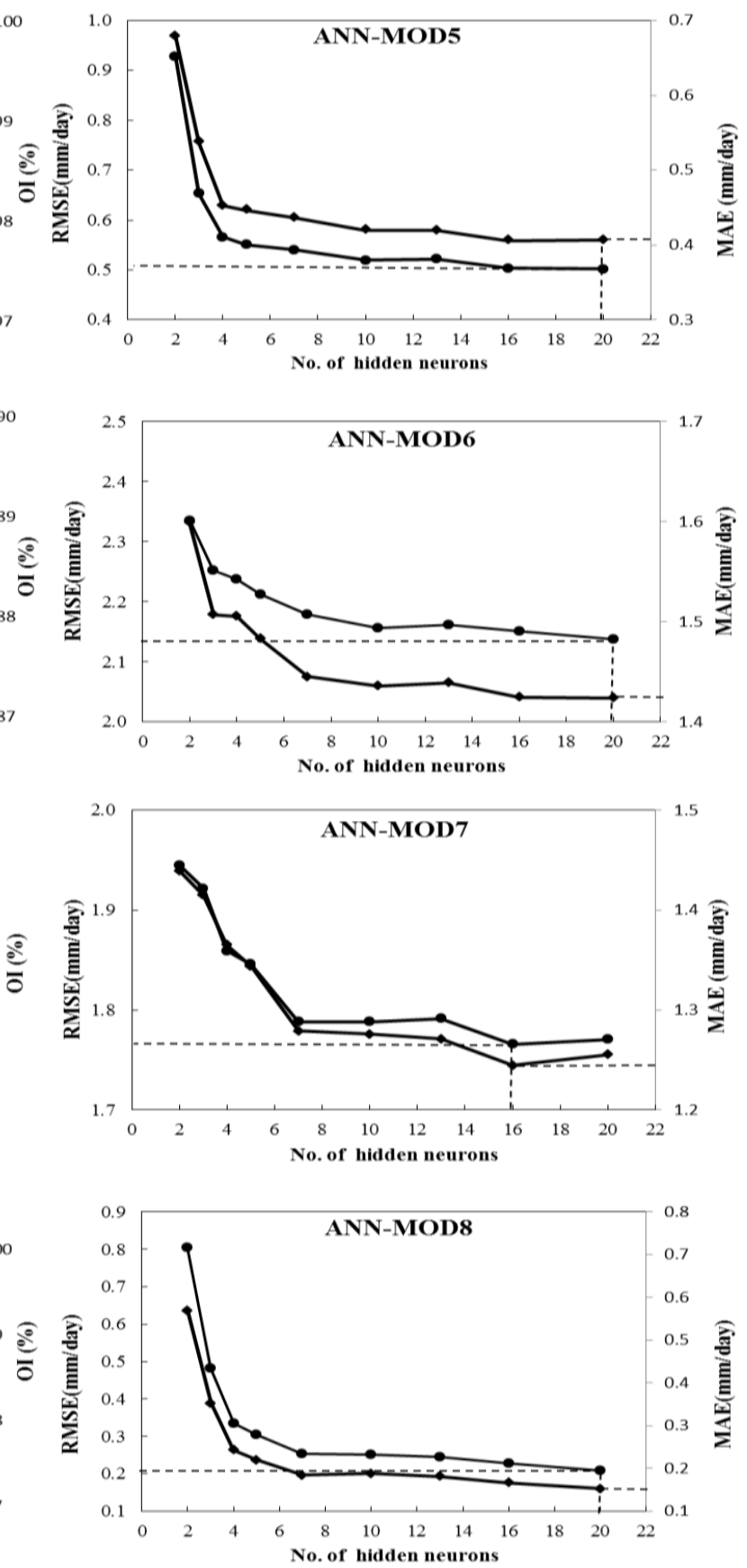

Figure 4. Accuracy of ANN-MOD5, ANN-MOD6, ANN-MOD7, and ANN-MOD8 in modeling the ET ref using different numbers of hidden neurons during training, measured with $R^{2}, O I, R M S E$ and $M A E$. 
neurons, generating the maximum $R^{2}(68.0 \%)$ and $O I$ $(80.7 \%)$ values and the minimum $R M S E(2.95 \mathrm{~mm} / \mathrm{d})$ and $M A E(2.13 \mathrm{~mm} / \mathrm{d})$ values for the training set, as shown in Figure 3. The best ANN-MOD1 model for forecasting the daily $\mathrm{ET}_{\mathrm{ref}}$ is composed of one input layer with four input variables, the daily maximum, mean, and minimum air temperature and the crop height, one hidden layer with 20 neurons and one output layer with one output variable. The rest of the ANN models were also tested to determine the optimum number of neurons in their hidden layers. The best ANN models for each input combination and their performance statistics on the training data set are shown in Figures 3 and 4.

The following steps were used to formulate the ANN models:

$$
\mathrm{ET}_{\text {ref(ANN-MOD } k)}=\frac{\left(\mathrm{ET}_{\text {ref }}\right)_{n k}-0.15}{(0.85-0.15)} \times\left(\mathrm{ET}_{\text {ref max }}-\mathrm{ET}_{\text {ref min }}\right)+\mathrm{ET}_{\text {ref min }}
$$

where $\left(\mathrm{ET}_{r e f}\right)_{n k}$ is the normalized value and $\mathrm{ET}_{\text {ref(ANN-MODk) is }}$ the actual value for the $\mathrm{ET}_{\text {ref }}$ in any model. The $\mathrm{ET}_{\text {ref max }}$ is $45.72 \mathrm{~mm} /$ day and the $\mathrm{ET}_{\text {ref } \min }$ is $0.46 \mathrm{~mm} /$ day.

$$
\mathrm{ET}_{\text {ref(ANN-MOD } k)}=\frac{\left(\mathrm{ET}_{\text {ref }}\right)_{\mathrm{n} k}-0.15}{(0.85-0.15)} \times(45.72-0.46)+0.46
$$

Eq. 14 is further simplified to:

$$
\begin{aligned}
& \mathrm{ET}_{\text {ref(ANN-MOD } k)}=64.65\left(\mathrm{ET}_{\mathrm{ref}}\right)_{n k}-9.24 \\
& \left(\mathrm{ET}_{\mathrm{ref}}\right)_{n k}=\left(1+\exp \left(-\left(\sum_{j=1}^{N} W_{j k} F_{j}+B_{k}\right)\right)\right)^{-1}
\end{aligned}
$$

where the weights $\left(W_{j k}\right)$ and the biases $\left(B_{k}\right)$ are given in Table A1. The parameter $F_{j}$ is computed from:

$$
F_{j}=\left(1+\exp \left(-\left(\sum_{i=1}^{n} w_{i j} x_{i}+b_{j}\right)\right)\right)^{-1}
$$

where the weights $\left(w_{i j}\right)$ and the biases $\left(b_{j}\right)$ are given in Tables A2-A9 and $x_{i}$ is the input variable. The subscripts $i, j$ and $k$ represent the number of input, hidden and output neurons, respectively. The mathematical formulations are easily

\begin{tabular}{|c|c|c|c|c|c|c|c|c|c|c|c|c|c|c|c|c|c|c|c|c|c|}
\hline \multirow{2}{*}{$\begin{array}{c}\text { Model } \\
\text {, K }\end{array}$} & \multirow{2}{*}{$\begin{array}{c}\text { Biase } \\
\text { B }_{k}\end{array}$} & \multicolumn{20}{|c|}{ Weights from the hidden layer to the output layer } \\
\hline & & Wk1 & $\mathbf{W}_{\mathbf{k} 2}$ & $\mathbf{W}_{\mathbf{k} 3}$ & $\mathbf{W}_{\mathbf{k} \mathbf{4}}$ & Wk5 & Wk6 & Wk7 & Wk8 & Wk9 & Wk10 & Wk11 & $\mathbf{W}_{\mathbf{k} 12}$ & $\mathbf{W}_{\mathbf{k 1 3}}$ & Wk14 & Wk15 & Wk16 & $\mathbf{W}_{\mathbf{k} 17}$ & Wk18 & Wk19 & $\mathbf{W}_{\mathbf{k} 20}$ \\
\hline 1 & 1.60 & -1.95 & 0.77 & -0.02 & 0.37 & 1.44 & -0.96 & -0.12 & -0.95 & -4.44 & 0.20 & 2.07 & 1.53 & -0.87 & 1.98 & -0.01 & 0.76 & 2.02 & 2.36 & -0.07 & -7.13 \\
\hline 2 & 4.87 & -0.48 & 0.12 & -0.21 & 0.35 & -10.96 & 0.31 & -0.32 & -0.52 & -6.62 & -0.63 & -0.10 & -0.33 & -0.90 & -0.66 & 0.68 & -3.26 & - & - & - & - \\
\hline 3 & 0.59 & -0.29 & 1.24 & -1.16 & -1.77 & -1.11 & 0.78 & -0.66 & 1.51 & -1.13 & -2.74 & -0.66 & -0.12 & -0.56 & -1.00 & -2.68 & 1.30 & - & - & - & - \\
\hline 4 & 0.06 & 0.70 & -0.16 & -2.35 & 0.31 & -4.90 & -2.58 & 4.61 & 1.45 & -1.39 & 0.16 & -0.64 & -0.73 & -0.51 & - & - & - & - & - & - & - \\
\hline 5 & -0.11 & 0.26 & -4.75 & -0.63 & -0.83 & -0.65 & -0.48 & 0.09 & -2.30 & -0.68 & 0.50 & 2.49 & -0.70 & -0.88 & -1.58 & -1.23 & -0.31 & -0.14 & 1.29 & 0.81 & -0.90 \\
\hline 6 & 0.78 & -8.75 & -0.64 & -1.55 & -3.03 & 1.16 & 3.15 & -0.47 & 2.83 & 0.32 & 2.17 & 1.90 & -6.84 & 2.10 & 1.66 & 0.37 & 0.52 & 1.69 & -3.48 & 0.27 & -0.69 \\
\hline 7 & 0.35 & -0.43 & -1.08 & -1.24 & -0.58 & -4.32 & 0.44 & -0.74 & 0.44 & 3.02 & -1.09 & -2.50 & 0.81 & -1.78 & 2.33 & -2.97 & 0.88 & - & - & - & - \\
\hline 8 & 0.77 & 7.27 & -1.83 & -0.39 & -1.01 & -0.48 & -0.60 & -5.70 & -0.64 & -2.29 & 1.54 & -0.37 & -10.96 & -0.92 & -0.72 & 0.76 & -0.34 & -1.71 & 1.02 & 0.41 & -0.86 \\
\hline
\end{tabular}
programmed in a spreadsheet (i.e. Microsoft Excel) or in the Visual Basic programming language to predict the $\mathrm{ET}_{\text {ref }}$ using

\begin{tabular}{|c|c|c|c|c|c|}
\hline \multirow{2}{*}{$\begin{array}{l}\text { No. of hidden } \\
\text { neuron, } \mathbf{j}\end{array}$} & \multirow[t]{2}{*}{ bias $\left(\mathbf{b}_{\mathbf{j}}\right)$} & \multicolumn{4}{|c|}{ Weights from the input layer to the hidden layer } \\
\hline & & $\mathbf{W} \mathbf{j} 1$ & $\mathbf{w}_{\mathbf{j} 2}$ & $\mathbf{w j 3}$ & $\mathbf{w}_{\mathbf{j} 4}$ \\
\hline 1 & -1.967 & 9.021 & -0.438 & 4.496 & 0.087 \\
\hline 2 & -6.203 & -0.198 & 0.977 & 0.188 & 0.932 \\
\hline 3 & -0.322 & -0.709 & 2.298 & -0.104 & -0.009 \\
\hline 4 & -0.700 & -1.197 & 0.180 & 3.473 & 0.342 \\
\hline 5 & -1.443 & -0.058 & 0.130 & 1.210 & 1.615 \\
\hline 6 & -0.559 & -1.852 & 4.163 & -0.428 & 4.257 \\
\hline 7 & 2.706 & -0.498 & 2.699 & -0.409 & -0.107 \\
\hline 8 & 4.147 & 0.148 & 8.311 & -0.590 & 0.933 \\
\hline 9 & -3.496 & 0.116 & -0.469 & 0.524 & -2.731 \\
\hline 10 & 0.095 & 1.585 & 0.491 & 0.157 & 2.623 \\
\hline 11 & 5.305 & -0.423 & 0.247 & 0.566 & 0.211 \\
\hline 12 & 1.750 & 0.306 & 0.854 & -0.713 & 0.416 \\
\hline 13 & -1.992 & 5.337 & -12.615 & 5.084 & 0.119 \\
\hline 14 & -1.339 & 0.020 & 0.608 & -0.043 & 0.852 \\
\hline 15 & -1.714 & 0.003 & 1.735 & 0.100 & 0.762 \\
\hline 16 & -0.052 & 3.913 & 1.203 & 1.420 & 0.955 \\
\hline 17 & 0.043 & 2.345 & 5.230 & 4.710 & 0.301 \\
\hline 18 & 0.250 & -4.001 & 2.533 & 0.615 & 1.075 \\
\hline 19 & 1.961 & -0.336 & 1.998 & -0.348 & 0.148 \\
\hline 20 & 5.628 & -1.053 & 1.013 & -0.751 & -0.120 \\
\hline
\end{tabular}
Equations 9-13, along with Tables A1 and A2-A9.

Table A1. Biases and Weights for ANN models at the output layer.

Table A2. Biases and Weights for ANN-MOD1. 
Table A3. Biases and Weights for ANN-MOD2.

\begin{tabular}{|c|c|c|c|c|c|c|c|c|}
\hline \multirow{2}{*}{$\begin{array}{c}\text { No. of } \\
\text { hidden } \\
\text { neuron, } \mathbf{j}\end{array}$} & \multirow[t]{2}{*}{ bias $\left(\mathbf{b}_{\mathbf{j}}\right)$} & \multicolumn{7}{|c|}{ Weights from the input layer to the hidden layer } \\
\hline & & $\mathbf{W}_{\mathbf{j} 1}$ & $\mathbf{w}_{\mathbf{j} 2}$ & $\mathbf{w} \mathbf{3}$ & $\mathbf{W}_{\mathrm{j} 4}$ & $\mathbf{w}_{\mathbf{j} 5}$ & $\mathbf{W}_{\mathrm{j} 6}$ & $\mathbf{W}_{\mathbf{j} 7}$ \\
\hline 1 & -8.628 & 2.955 & 5.786 & 1.159 & 2.147 & -2.737 & -0.852 & 0.405 \\
\hline 2 & -5.142 & 0.533 & 6.747 & -2.948 & -0.170 & 2.776 & -10.320 & 1.744 \\
\hline 3 & -6.543 & 0.753 & 7.173 & 2.473 & 8.572 & 2.090 & 1.329 & -0.758 \\
\hline 4 & -7.595 & 1.591 & 5.997 & 7.982 & 5.857 & 4.222 & -2.187 & 0.135 \\
\hline 5 & -1.152 & -0.028 & -0.159 & -0.488 & 0.066 & -0.011 & 0.107 & -0.148 \\
\hline 6 & -4.225 & -0.890 & 4.904 & 1.961 & -3.746 & 4.431 & -1.934 & 0.284 \\
\hline 7 & -11.651 & 2.166 & 11.014 & -5.425 & -4.370 & 1.192 & -10.048 & -0.274 \\
\hline 8 & -16.890 & 16.192 & 5.106 & -5.225 & -0.271 & -1.131 & -2.424 & 1.968 \\
\hline 9 & -5.193 & -0.324 & 1.448 & -0.933 & -0.088 & -0.050 & -0.408 & -2.499 \\
\hline 10 & -7.185 & 15.265 & -1.438 & 2.879 & -4.531 & 8.553 & 0.996 & 0.419 \\
\hline 11 & 11.237 & -11.098 & -12.585 & -9.846 & -12.125 & 1.294 & -13.789 & 0.287 \\
\hline 12 & -5.550 & 4.283 & 4.924 & 3.156 & -0.894 & 4.329 & 7.202 & 0.365 \\
\hline 13 & -3.454 & 0.067 & -0.179 & -0.506 & 3.865 & 1.801 & -0.912 & 0.579 \\
\hline 14 & 3.222 & -1.194 & -11.912 & 13.334 & 0.901 & 3.244 & 0.009 & -0.155 \\
\hline 15 & -4.070 & 11.519 & -1.951 & -0.794 & -2.194 & 4.208 & 0.534 & 0.278 \\
\hline 16 & 6.846 & -3.020 & -3.736 & 1.332 & 1.243 & 0.027 & -0.041 & -1.252 \\
\hline
\end{tabular}

Table A4. Biases and Weights for ANN-MOD3.

\begin{tabular}{|c|c|c|c|c|c|c|}
\hline \multirow{2}{*}{$\begin{array}{c}\text { No. of hidden } \\
\text { neuron, } \mathbf{j}\end{array}$} & \multirow[t]{2}{*}{ bias $\left(\mathbf{b}_{\mathbf{j}}\right)$} & \multicolumn{5}{|c|}{ Weights from the input layer to the hidden layer } \\
\hline & & $w_{\mathrm{ji}}$ & $w_{\mathrm{j} 2}$ & $w_{\mathrm{j} 3}$ & $w_{\mathrm{j} 4}$ & $w_{\mathrm{j} 5}$ \\
\hline 1 & -3.280 & 29.503 & 10.441 & -37.704 & 0.967 & 0.262 \\
\hline 2 & 1.583 & 1.501 & -1.059 & 1.229 & 1.915 & -0.634 \\
\hline 3 & -0.858 & -8.260 & 12.099 & -5.928 & 0.614 & 0.484 \\
\hline 4 & 3.669 & 0.939 & -2.374 & -2.779 & -2.658 & -0.813 \\
\hline 5 & -0.305 & -1.965 & 3.844 & -5.192 & 2.304 & -0.244 \\
\hline 6 & -0.830 & -0.652 & -0.434 & 0.958 & 0.905 & 2.295 \\
\hline 7 & -1.035 & -4.925 & -13.450 & 14.654 & 1.127 & 0.322 \\
\hline 8 & -0.898 & 0.596 & -0.800 & 1.424 & -1.310 & 0.638 \\
\hline 9 & -1.687 & -1.350 & 0.638 & 0.726 & -1.050 & 0.223 \\
\hline 10 & -4.001 & 0.027 & -0.519 & 0.114 & 0.856 & -3.464 \\
\hline 11 & -0.752 & -1.603 & 0.780 & 0.385 & 0.054 & -0.023 \\
\hline 12 & -0.444 & -3.693 & 0.085 & -1.394 & 2.125 & 0.642 \\
\hline 13 & -0.068 & -0.562 & -0.113 & -0.723 & -0.208 & 0.312 \\
\hline 14 & -1.014 & -0.788 & 0.550 & -0.208 & -0.938 & -0.093 \\
\hline 15 & -3.035 & 0.980 & 0.110 & -0.457 & -2.718 & -0.124 \\
\hline 16 & -0.849 & -3.939 & 12.736 & -12.426 & 1.889 & -0.089 \\
\hline
\end{tabular}

Table A5. Biases and Weights for ANN-MOD4.

\begin{tabular}{|c|c|c|c|c|c|c|}
\hline \multirow{2}{*}{$\begin{array}{l}\text { No. of hidden } \\
\text { neuron, } \mathbf{j}\end{array}$} & \multirow[t]{2}{*}{ bias $\left(\mathbf{b}_{\mathbf{j}}\right)$} & \multicolumn{5}{|c|}{ Weights from the input layer to the hidden layer } \\
\hline & & $w_{\mathrm{ji}}$ & $w_{\mathrm{j} 2}$ & $w_{\mathrm{j} 3}$ & $w_{\mathrm{j} 4}$ & $w_{\mathrm{j} 5}$ \\
\hline 1 & -2.057 & -1.846 & 0.778 & 0.950 & -0.108 & 2.967 \\
\hline 2 & -8.766 & -5.698 & 21.721 & 2.622 & -1.565 & 1.678 \\
\hline 3 & -1.799 & -3.122 & 0.668 & 0.634 & -1.097 & 0.408 \\
\hline 4 & -1.006 & -1.253 & 2.222 & -1.074 & 1.454 & 3.587 \\
\hline 5 & -3.871 & 0.371 & -0.274 & -0.204 & -0.284 & -2.557 \\
\hline 6 & -1.223 & -0.030 & -1.915 & -0.115 & 0.944 & 0.339 \\
\hline 7 & -8.255 & -2.636 & 4.681 & -1.770 & 5.936 & 0.451 \\
\hline 8 & -4.047 & -2.072 & 3.937 & 5.138 & -1.865 & 0.375 \\
\hline 9 & -3.578 & -4.865 & 9.281 & -2.484 & 0.068 & 0.680 \\
\hline 10 & 11.504 & 6.039 & -14.710 & -14.474 & -2.430 & -0.062 \\
\hline 11 & 1.072 & 4.420 & -0.997 & -0.401 & -5.181 & -0.033 \\
\hline 12 & 2.889 & -10.626 & 4.170 & -3.928 & 1.292 & 0.461 \\
\hline 13 & -2.892 & 3.218 & 1.706 & 7.044 & -0.372 & -0.169 \\
\hline
\end{tabular}


Table A6. Biases and Weights for ANN-MOD5.

\begin{tabular}{|c|c|c|c|c|c|c|c|c|c|}
\hline \multirow{2}{*}{$\begin{array}{c}\text { No. of } \\
\text { hidden } \\
\text { neuron, } \mathrm{j}\end{array}$} & \multirow[t]{2}{*}{ bias $\left(\mathbf{b}_{\mathbf{j}}\right)$} & \multicolumn{8}{|c|}{ Weights from the input layer to the hidden layer } \\
\hline & & $\mathbf{W}_{\mathbf{j} 1}$ & $\mathbf{W}_{\mathbf{j} 2}$ & $\mathbf{W} \mathbf{3}$ & $\mathbf{W}_{\mathbf{j} 4}$ & $\mathbf{W}_{\mathbf{j} 5}$ & Wj6 & $\mathbf{W}_{\mathbf{j} 7}$ & $\mathbf{W j 8}$ \\
\hline 1 & -1.967 & 6.977 & -0.332 & 2.074 & -0.554 & 2.946 & 0.347 & 0.082 & -0.065 \\
\hline 2 & -6.203 & 0.444 & 0.599 & -1.098 & -0.626 & 0.137 & -0.059 & -4.585 & 0.245 \\
\hline 3 & -0.322 & -1.587 & -0.008 & 0.075 & 0.657 & -0.085 & -0.462 & -0.443 & 0.306 \\
\hline 4 & -0.700 & -0.597 & 0.353 & -0.428 & 0.564 & 1.242 & -0.558 & 0.444 & 0.066 \\
\hline 5 & -1.443 & -0.551 & -0.410 & 0.264 & -0.776 & 0.492 & -0.500 & 0.503 & -1.415 \\
\hline 6 & -0.559 & -1.609 & -0.884 & 2.820 & -0.352 & 1.215 & -0.367 & 0.420 & -0.129 \\
\hline 7 & 2.706 & 6.443 & -2.903 & 3.604 & -0.188 & 2.328 & 7.614 & 3.931 & 0.469 \\
\hline 8 & 4.147 & -2.855 & -1.590 & 1.856 & 1.159 & 0.562 & 0.000 & -2.617 & -1.311 \\
\hline 9 & -3.496 & -3.850 & -1.301 & -1.107 & 0.418 & 0.009 & 0.755 & -0.136 & -0.279 \\
\hline 10 & 0.095 & -1.374 & -0.645 & 0.719 & 0.650 & 0.451 & 2.266 & 0.007 & -0.134 \\
\hline 11 & 5.305 & -0.387 & -0.113 & 0.680 & 0.297 & 0.119 & -0.277 & -0.993 & 5.807 \\
\hline 12 & 1.750 & -0.952 & -1.248 & -0.735 & 0.432 & 0.198 & 0.877 & 1.831 & -0.054 \\
\hline 13 & -1.992 & -0.891 & -0.702 & 1.225 & 0.353 & -0.414 & -0.934 & -0.788 & -0.189 \\
\hline 14 & -1.339 & 0.971 & -1.548 & -0.197 & 1.700 & 0.737 & -0.298 & 1.958 & 0.490 \\
\hline 15 & -1.714 & 1.391 & 0.415 & -2.335 & 0.301 & -0.299 & 1.522 & -0.640 & -0.394 \\
\hline 16 & -0.052 & -4.411 & -2.231 & 0.170 & -0.201 & 0.222 & 0.884 & -1.446 & -0.229 \\
\hline 17 & 0.043 & -1.668 & 1.638 & 0.694 & -1.079 & 1.470 & 0.578 & 0.197 & -0.735 \\
\hline 18 & 0.250 & 0.013 & 0.776 & -1.331 & -0.501 & -0.442 & -0.391 & 2.080 & 0.880 \\
\hline 19 & 1.961 & -0.359 & -0.852 & -0.607 & -0.309 & 0.016 & -0.809 & 1.836 & 0.242 \\
\hline 20 & 5.628 & 0.045 & 0.167 & 0.312 & 0.274 & 0.010 & -0.252 & -1.047 & 7.787 \\
\hline
\end{tabular}

Table A7. Biases and Weights for ANN-MOD6.

\begin{tabular}{|c|c|c|c|c|c|c|c|c|c|}
\hline \multirow{2}{*}{$\begin{array}{c}\begin{array}{c}\text { No. of } \\
\text { hidden } \\
\text { neuron, } \mathrm{j}\end{array} \\
\end{array}$} & \multirow[t]{2}{*}{$\operatorname{bias}\left(\mathbf{b}_{\mathbf{j}}\right)$} & \multicolumn{8}{|c|}{ Weights from the input layer to the hidden layer } \\
\hline & & $\mathbf{W} \mathbf{j} 1$ & $\mathbf{W} \mathbf{2} 2$ & $\mathbf{W j 3}$ & $\mathbf{W j 4}$ & Wj5 & Wj6 & $\mathbf{W j 7}$ & $\mathbf{W j 8}$ \\
\hline 1 & -4.521 & 0.504 & 1.616 & -1.945 & -0.181 & -0.293 & -0.088 & 0.058 & -1.836 \\
\hline 2 & -4.231 & 3.227 & 5.027 & -5.084 & 3.567 & 0.047 & 1.003 & -0.308 & 0.415 \\
\hline 3 & -23.004 & 3.234 & 5.148 & 3.960 & -1.325 & -0.413 & -3.751 & 8.852 & 1.194 \\
\hline 4 & -10.916 & 1.017 & 8.772 & 4.385 & -5.703 & 5.515 & 2.598 & -0.105 & 0.281 \\
\hline 5 & -9.806 & -2.830 & 5.234 & 7.152 & -0.539 & 1.491 & -0.930 & 1.043 & 0.316 \\
\hline 6 & -12.175 & 3.544 & 12.067 & -11.253 & -5.974 & -0.085 & -0.196 & 1.139 & 1.157 \\
\hline 7 & -10.787 & -0.007 & 4.443 & 1.237 & -6.313 & 2.815 & -8.010 & -0.570 & 0.297 \\
\hline 8 & -15.188 & -5.425 & 10.754 & 3.024 & 1.562 & 1.127 & -4.302 & 3.193 & 1.603 \\
\hline 9 & -3.177 & -11.991 & -1.004 & 14.030 & -0.293 & -0.338 & -1.751 & -1.286 & 2.557 \\
\hline 10 & -4.109 & 4.714 & -2.094 & 0.505 & -2.083 & 1.590 & 1.404 & -0.748 & 1.386 \\
\hline 11 & -12.182 & -3.961 & 6.104 & 6.575 & 0.177 & 0.961 & -1.691 & 1.717 & 0.872 \\
\hline 12 & -0.975 & -0.153 & -0.930 & 0.126 & 0.301 & 0.199 & 0.029 & -0.277 & -0.104 \\
\hline 13 & -9.110 & -0.035 & 3.205 & 5.347 & 0.550 & 2.434 & 1.341 & -0.943 & -1.222 \\
\hline 14 & -12.911 & 2.982 & 7.076 & -3.213 & -3.648 & -1.816 & 4.177 & 3.374 & 1.107 \\
\hline 15 & -3.717 & 11.371 & 21.022 & -29.622 & -1.075 & -0.438 & -1.332 & 0.606 & 0.421 \\
\hline 16 & -9.532 & -5.748 & 4.206 & 5.290 & -10.150 & 0.397 & 0.022 & -0.408 & -0.498 \\
\hline 17 & -10.297 & -1.288 & 4.792 & 5.413 & -0.938 & 1.546 & -0.554 & 1.218 & 0.187 \\
\hline 18 & -5.218 & 0.791 & -0.612 & 0.706 & -0.476 & -0.029 & -1.289 & -0.830 & -0.152 \\
\hline 19 & -7.188 & 14.386 & -14.106 & 5.796 & 2.538 & -2.205 & -2.629 & -8.715 & 0.531 \\
\hline 20 & 15.850 & -1.972 & -2.721 & 1.864 & 1.445 & 1.321 & -0.397 & -11.818 & -0.871 \\
\hline
\end{tabular}


Table A8. Biases and Weights for ANN-MOD7.

\begin{tabular}{|c|c|c|c|c|c|c|c|}
\hline \multirow{2}{*}{$\begin{array}{c}\text { No. of hidden } \\
\text { neuron, } \mathbf{j}\end{array}$} & \multirow[t]{2}{*}{ bias $\left(\mathbf{b}_{\mathbf{j}}\right)$} & \multicolumn{6}{|c|}{ Weights from the input layer to the hidden layer } \\
\hline & & $\mathbf{w} \mathbf{j 1}$ & $\mathbf{W} \mathbf{2}$ & $\mathbf{w} \mathbf{3}$ & $\mathbf{W j 4}$ & $\mathbf{W}_{\mathbf{j} 5}$ & Wj6 \\
\hline 1 & 4.887 & -2.879 & 4.062 & -1.826 & 7.762 & -0.037 & -0.359 \\
\hline 2 & -0.531 & -1.191 & -6.410 & 3.966 & 1.640 & -0.601 & 0.323 \\
\hline 3 & -3.696 & 0.823 & -0.329 & 2.014 & 3.153 & 1.943 & -1.195 \\
\hline 4 & -2.638 & 17.962 & 3.787 & -17.283 & 2.877 & -0.232 & 0.471 \\
\hline 5 & -2.500 & 0.151 & -0.337 & -0.156 & -2.241 & -0.239 & -0.077 \\
\hline 6 & -4.915 & -19.695 & 22.119 & -10.330 & -2.032 & 1.781 & -0.008 \\
\hline 7 & 0.801 & -6.742 & 0.693 & 5.204 & 4.953 & -0.130 & -0.453 \\
\hline 8 & 0.071 & 0.225 & 0.481 & 0.198 & 1.506 & -0.932 & 1.364 \\
\hline 9 & -4.077 & -1.204 & 3.695 & 2.641 & 1.449 & -1.233 & 0.901 \\
\hline 10 & 5.236 & 2.197 & -4.159 & -0.979 & -2.776 & -4.461 & -0.100 \\
\hline 11 & -6.899 & 0.413 & -0.266 & -0.429 & 1.021 & -0.461 & -6.169 \\
\hline 12 & 0.816 & -0.118 & -0.318 & 0.587 & 2.514 & -0.121 & 0.482 \\
\hline 13 & -1.159 & -3.847 & 4.591 & -2.535 & 0.097 & -0.358 & 0.107 \\
\hline 14 & -0.742 & 0.862 & 1.114 & 0.018 & 1.950 & -0.099 & 0.410 \\
\hline 15 & -2.521 & -2.534 & 4.128 & 0.442 & 0.549 & -0.009 & 0.837 \\
\hline 16 & -0.547 & 0.451 & -0.764 & -0.594 & -0.187 & 0.418 & 0.701 \\
\hline
\end{tabular}

Table A9. Biases and Weights for ANN-MOD8.

\begin{tabular}{|c|c|c|c|c|c|c|c|c|c|c|}
\hline \multirow{2}{*}{$\begin{array}{c}\begin{array}{c}\text { No. of } \\
\text { hidden } \\
\text { neuron, } \mathrm{j}\end{array} \\
\end{array}$} & \multirow{2}{*}{$\begin{array}{c}\text { bias } \\
\left(\mathbf{b}_{\mathbf{j}}\right)\end{array}$} & \multicolumn{9}{|c|}{ Weights from the input layer to the hidden layer } \\
\hline & & $\mathbf{W} \mathbf{j} 1$ & $\mathbf{W} \mathbf{j} 2$ & $\mathbf{W j 3}$ & $\mathbf{W j 4}$ & $\mathbf{W j 5}$ & Wj6 & $\mathbf{W j 7}$ & $\mathbf{W j 8}$ & $\mathbf{W j 9}$ \\
\hline 1 & -5.361 & 2.163 & 1.185 & -1.071 & -1.072 & -0.388 & -0.083 & 1.978 & 0.229 & 1.037 \\
\hline 2 & -2.492 & 1.283 & -1.196 & -0.424 & 1.558 & 0.034 & -0.241 & 0.111 & -0.467 & 0.249 \\
\hline 3 & -0.805 & 0.426 & -0.152 & -1.311 & 0.871 & 0.297 & 0.670 & -1.253 & 0.601 & -0.556 \\
\hline 4 & -1.065 & -0.662 & -0.726 & 1.182 & 0.910 & 0.668 & -0.216 & -2.551 & 0.848 & -0.723 \\
\hline 5 & -0.928 & 0.318 & 0.283 & 1.037 & -0.402 & 0.120 & 0.449 & -2.206 & -0.925 & -0.416 \\
\hline 6 & 0.264 & -1.054 & -0.703 & 0.488 & 0.899 & 0.377 & -0.519 & -1.709 & -0.544 & 0.881 \\
\hline 7 & -7.374 & 0.203 & 0.337 & -0.571 & -0.588 & -0.273 & 0.154 & -5.405 & -0.465 & 0.206 \\
\hline 8 & -1.336 & -0.949 & -0.301 & -0.869 & -0.247 & 0.712 & -0.513 & 0.048 & -0.864 & -0.230 \\
\hline 9 & -3.748 & 0.989 & -0.913 & -0.101 & 1.622 & 2.107 & 0.071 & 0.719 & -0.362 & 0.294 \\
\hline 10 & -1.658 & 1.356 & 0.450 & -1.637 & -0.915 & -0.513 & 0.126 & 1.220 & -1.511 & 0.466 \\
\hline 11 & -0.488 & 0.214 & -0.928 & -0.594 & 0.246 & 0.143 & 0.330 & 0.024 & -1.448 & 0.133 \\
\hline 12 & -9.374 & 0.111 & 0.039 & -0.337 & -0.024 & -0.014 & -0.026 & 0.524 & -0.044 & -7.406 \\
\hline 13 & 10.179 & -0.074 & -0.001 & 0.251 & -0.308 & -0.154 & 0.324 & 0.195 & -0.115 & 10.418 \\
\hline 14 & -0.676 & 0.516 & -0.137 & -0.540 & -0.056 & -0.007 & -0.248 & 1.862 & -0.195 & -1.662 \\
\hline 15 & 0.857 & 1.481 & -0.755 & 0.036 & 0.931 & 0.509 & 0.289 & 2.129 & 0.554 & 0.204 \\
\hline 16 & -1.094 & 0.700 & -0.557 & -1.030 & 0.494 & 0.353 & 1.428 & 0.567 & 0.334 & -0.730 \\
\hline 17 & -0.740 & -0.657 & -0.772 & -0.178 & 0.311 & 0.018 & 0.124 & 1.827 & -0.191 & 0.196 \\
\hline 18 & -1.937 & 1.308 & 0.983 & -0.411 & -0.805 & -0.276 & 0.139 & -1.887 & 0.333 & 0.331 \\
\hline 19 & -0.362 & -0.995 & -2.051 & 0.267 & 1.578 & 0.365 & -0.302 & -0.125 & -0.342 & -0.653 \\
\hline 20 & -3.082 & 0.235 & 0.474 & 0.293 & -1.213 & -0.762 & 0.147 & -1.064 & -0.522 & -0.528 \\
\hline
\end{tabular}



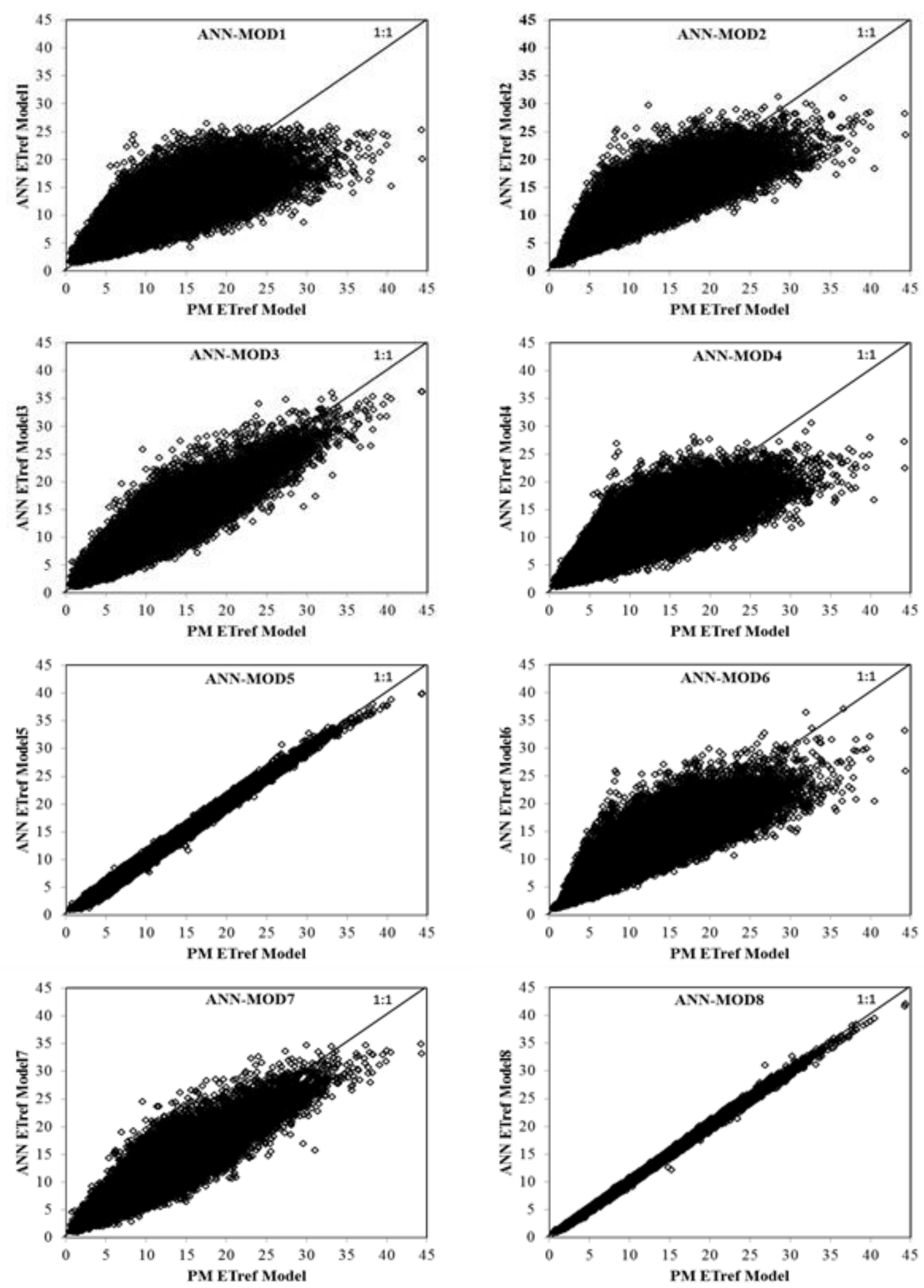

Figure 5. Comparison of the daily $\mathbf{E T}_{\text {ref }}$ estimated using the ANN models with different input combinations during training process and the PMG equation, using 65\% of the data collected from 1980 to $2010 \mathrm{Jby} 13$ meteorological stations. 


\section{ANN Models Performance:}

Training and testing processes: Figure 5 shows that the daily $\mathrm{ET}_{\text {ref }}$ values estimated by the ANN models that used $\mathrm{U}_{2}$ during the training process matched well with each other and the values estimated by the PMG model. The effectiveness of these models is clear. The scatter plots for the training process in Figure 5 also show that the ANN-MOD5 and ANN-MOD8 data mostly follow the $45^{\circ}$ line. However, many points in the ANN models that do not use $\mathrm{U}_{2}$ are located above and below this line.

Table 3 presents the statistical results of the optimum ANN models using different input combinations to estimate the $\mathrm{ET}_{\text {ref. }}$ In training, it can be observed that the absence or presence of some of the input variables in the input sets significantly affects the models' performances. The ANNMOD1 temperature-based model only took the three temperature variables. ANN-MOD1 performed worst, with $R^{2}$ of $67.9 \%, O I$ of $80.6 \%, R M S E$ of $2.95 \mathrm{~mm} / \mathrm{d}$ and $M A E$ of 2.12 $\mathrm{mm} / \mathrm{d}$ (Table 3). The ANN-MOD2 performed better than ANN-MOD1 that had a $R^{2}$ and $O I$ values that were about $18 \%$ and $8.4 \%$ increase, due to the presence of the three humidity variables. While the ANN-MOD2 had an RMSE and MAE values that were about $21.4 \%$ and $25 \%$, respectively, more accurate than that from the ANN-MOD1. This is confirmed by the Figure 6 that shows an importance ratio analysis of each input parameter used in the calculation of the daily $\mathrm{ET}_{\text {ref. }}$. The figure shows that $\mathrm{T}_{\mathrm{n}}$ of $37.66 \%$ and $22.31 \%$ were the most significant parameters affecting ANN-MOD1 and ANNMOD2, respectively. As the average importance ratio of three humidity variables was $12.72 \%$ in ANN-MOD2.

Additionally, ANN-MOD3 predicative accuracy increased, whereas the $R^{2}$ was $87.1 \%$, a $28.3 \%$ and $8.6 \%$ increase over the $R^{2}$ values of ANN-MOD1 and ANN-MOD2, respectively. The rest of statistical criteria for the ANN-MOD3 confirm that $\mathrm{ET}_{\text {ref }}$ performs poorly without $\mathrm{U}_{2}$. The importance ratio of $\mathrm{U}_{2}$ and $\mathrm{T}_{\mathrm{n}}$ were also the second most influential variables, both nearly $19 \%$. Moreover ANN-MOD4, which added $\mathrm{R}_{\mathrm{s}}$ to the ANN-MOD1 combination, improved slightly on estimating $\mathrm{ET}_{\text {ref }}$ than ANN-MOD2. This is evident in Figure 6 that $\mathrm{T}_{\mathrm{n}}$ of $28.55 \%$ and $\mathrm{T}_{\mathrm{x}}$ of $24.28 \%$ were the dominant input variables.

However, inserting $\mathrm{U}_{2}$ into ANN-MOD2, as in ANN-MOD5, resulted in a dramatic increase in $R^{2}$ from $80.2 \%$ to $99.1 \%$, i.e. a $19.98 \%$ increase. The RMSE and MAE values indicate that the ANN-MOD5 performs better than the ANN-MOD2, indicating a decrease of $78.4 \%$ and $74.7 \%$, respectively. The value of $O I$ is close to one which supports the argument that the $\mathrm{ET}_{\text {ref }}$ can perform well without $\mathrm{R}_{\mathrm{s}}$. The $\mathrm{T}_{\mathrm{x}}$ of $20.32 \%$ and $\mathrm{U}_{2}$ of $17 \%$ had also the largest effect on ANN-MOD5 (Fig. 6). As, switching ANN-MOD5's $\mathrm{R}_{\mathrm{s}}$ for $\mathrm{U}_{2}$, as in ANNMOD6, resulted in a intense decrease in the values of $R^{2}$ and $O I$ that were $16.6 \%$ and $10.2 \%$ less accurate than that from the ANN-MOD5. The RMSE and MAE for ANN-MOD6 were almost three times that of the values for the ANN-MOD5. This is in accordance with Kişi and Ozturk (2007).

Comparing ANN-MOD7's results with those of the other ANN models shows that the accuracy of the ANN-MOD4 was significantly improved by the inclusion of $\mathrm{U}_{2}$, as ANNMOD7 had a $22.7 \%$ and $11.2 \%$ increase in the $R^{2}$ and $O I$ over ANN-MOD4, receptivity. The RMSE and MAE for ANNMOD7 had also $36.1 \%$ and $37.2 \% \%$ more accurate than that from the ANN-MOD4. $\mathrm{U}_{2}(24.49 \%)$ was the most significant parameters affecting ANN-MOD7. This is in agreement with Hupet and Vanclooster (2001). $U_{2}$ is likely to be an effective, powerful variable for accurately modelling the nonlinear complex process of $\mathrm{ET}_{\text {ref }}$ (Fisher et al., 2005; Xiaoying and Erda, 2005; Li and Beswick, 2005; Traore et al., 2010). On the other hand, the statistical criteria in Table 3 indicate that slight difference between the ANN-MOD6 and the ANNMOD2, also between the ANN-MOD7 and the ANN-MOD3. This shows that $\mathrm{R}_{\mathrm{s}}$ had an insignificant influence (about of 8.5\%) on estimating $\mathrm{ET}_{\text {ref. }}$ Finally, ANN-MOD8, which has the full input set similar to the PMG model, performs better than the rest of the ANN models, whereas the $R^{2}$ value indicated a strong fit to the data. The ANN-MOD8 yielded a highest $O I$ and a lowest $R M S E$ and MAE.

In testing, Table 3 show the results of adding either the three humidity variables (ANN-MOD2), $\mathrm{U}_{2}$ (ANN-MOD3) or $\mathrm{R}_{\mathrm{s}}$ (ANN-MOD4) to ANN-MOD1. ANNMOD2 and ANNMOD3 performed better than ANN-MOD1. A slightly worse performance was obtained for ANN-MOD4. This result indicates that $\mathrm{R}_{\mathrm{s}}$ had a slight effect on modelling the $\mathrm{ET}_{\text {ref, }}$ as the $R^{2}$ value increased by $6.65 \%$ only when $\mathrm{R}_{\mathrm{s}}$ was added to ANN-MOD1.

Table 3. Statistical performance of the optimized ANN models during training and testing.

\begin{tabular}{|c|c|c|c|c|c|c|c|c|c|}
\hline \multirow[t]{2}{*}{ Model } & \multirow[t]{2}{*}{ Inputs } & \multicolumn{4}{|c|}{ Training } & \multicolumn{4}{|c|}{ Testing } \\
\hline & & $\begin{array}{l}\mathbf{R}^{2} \\
(\%)\end{array}$ & $\begin{array}{l}\text { OI } \\
(\%)\end{array}$ & $\begin{array}{l}\text { RMSE } \\
(\mathrm{mm} / \mathrm{d})\end{array}$ & $\begin{array}{c}\text { MAE } \\
(\mathbf{m m} / \mathbf{d})\end{array}$ & $\begin{array}{c}\mathbf{R}^{2} \\
(\%)\end{array}$ & $\begin{array}{c}\text { OI } \\
(\%) \\
\end{array}$ & $\begin{array}{l}\text { RMSE } \\
(\mathrm{mm} / \mathrm{d})\end{array}$ & $\begin{array}{c}\text { MAE } \\
\text { (mm/d) }\end{array}$ \\
\hline ANN-MOD1 & $\mathrm{T}_{\mathrm{x}}, \mathrm{T}_{\mathrm{n}}, \mathrm{T}_{\mathrm{a}}, \mathrm{h}_{\mathrm{c}}$ & 67.9 & 0.806 & 2.95 & 2.12 & 67.6 & 0.803 & 3.00 & 2.20 \\
\hline ANN-MOD2 & $\mathrm{T}_{\mathrm{x}}, \mathrm{T}_{\mathrm{n}}, \mathrm{T}_{\mathrm{a}}, \mathrm{Rh}_{\mathrm{x}}, \mathrm{Rh}_{\mathrm{n}}, \mathrm{Rh}_{\mathrm{a}}, \mathrm{h}_{\mathrm{c}}$ & 80.2 & 0.874 & 2.32 & 1.59 & 80.4 & 0.875 & 2.33 & 1.61 \\
\hline ANN-MOD3 & $\mathrm{T}_{\mathrm{x}}, \mathrm{T}_{\mathrm{n}}, \mathrm{T}_{\mathrm{a}}, \mathrm{u}_{2}, \mathrm{~h}_{\mathrm{c}}$ & 87.1 & 0.914 & 1.87 & 1.35 & 87.1 & 0.914 & 1.89 & 1.33 \\
\hline ANN-MOD4 & $\mathrm{T}_{\mathrm{x}}, \mathrm{T}_{\mathrm{n}}, \mathrm{T}_{\mathrm{a}}, \mathrm{R}_{\mathrm{s}}, \mathrm{h}_{\mathrm{c}}$ & 72.2 & 0.830 & 2.74 & 1.96 & 72.1 & 0.827 & 2.78 & 2.04 \\
\hline ANN-MOD5 & $\mathrm{T}_{\mathrm{x}}, \mathrm{T}_{\mathrm{n}}, \mathrm{T}_{\mathrm{a}}, \mathrm{Rh_{ \textrm {x } }}, \mathrm{Rh}_{\mathrm{n}}, \mathrm{Rh}_{\mathrm{a}}, \mathrm{u}_{2}, \mathrm{~h}_{\mathrm{c}}$ & 99.1 & 0.989 & 0.50 & 0.40 & 99.1 & 0.989 & 0.51 & 0.41 \\
\hline ANN-MOD6 & $\mathrm{T}_{\mathrm{x}}, \mathrm{T}_{\mathrm{n}}, \mathrm{T}_{\mathrm{a}}, \mathrm{Rh}_{\mathrm{x}}, \mathrm{Rh}_{\mathrm{n}}, \mathrm{Rh}_{\mathrm{a}}, \mathrm{R}_{\mathrm{s}}, \mathrm{h}_{\mathrm{c}}$ & 82.6 & 0.888 & 2.17 & 1.45 & 82.3 & 0.885 & 2.22 & 1.53 \\
\hline ANN-MOD7 & $\mathrm{T}_{\mathrm{x}}, \mathrm{T}_{\mathrm{n}}, \mathrm{T}_{\mathrm{a}}, \mathrm{u}_{2}, \mathrm{R}_{\mathrm{s}}, \mathrm{h}_{\mathrm{c}}$ & 88.6 & 0.923 & 1.75 & 1.23 & 88.8 & 0.924 & 1.76 & 1.19 \\
\hline ANN-MOD8 & $\mathrm{T}_{\mathrm{x}}, \mathrm{T}_{\mathrm{n}}, \mathrm{T}_{\mathrm{a}}, \mathrm{Rh}_{\mathrm{x}}, \mathrm{Rh}_{\mathrm{n}}, \mathrm{Rh}_{\mathrm{a}}, \mathrm{u}_{2}, \mathrm{R}_{\mathrm{s}}, \mathrm{h}_{\mathrm{c}}$ & 99.8 & 0.996 & 0.21 & 0.15 & 99.8 & 0.997 & 0.19 & 0.14 \\
\hline
\end{tabular}




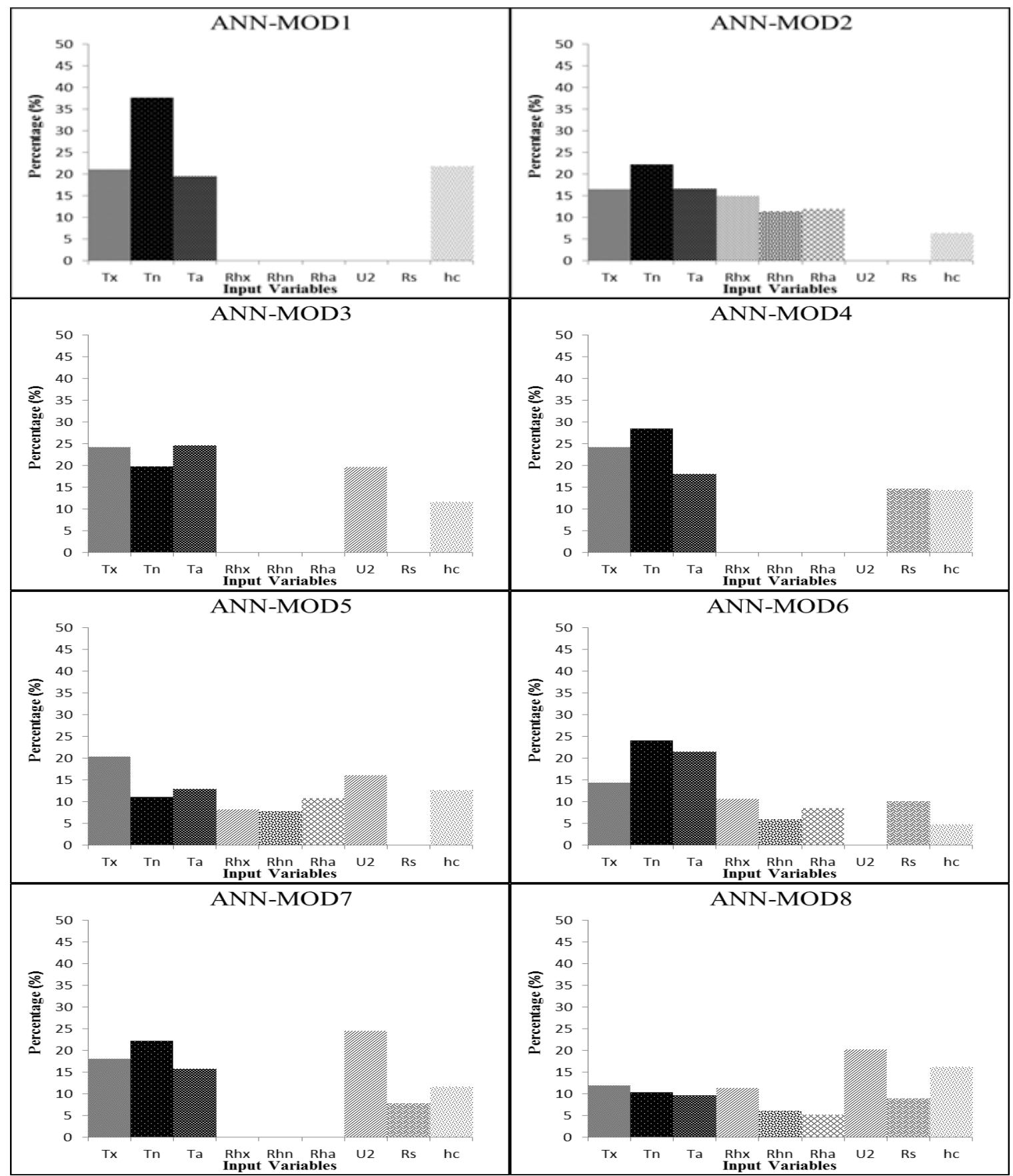

Figure 6. Importance ratio analysis of the input variables in the ANN models.

The relative humidity variables seemed to be more effective than $\mathrm{R}_{\mathrm{S}}$ in the modelling of the $\mathrm{ET}_{\text {ref, }}$, as the $R^{2}$ increased by $18.93 \%$ when the humidity variables were added to ANNMOD1. Adding $\mathrm{U}_{2}$ to the input combination improved the estimation accuracy significantly, due to its advection effects on the $\mathrm{ET}_{\text {ref }}$ (Kişi, 2007), as the $R^{2}$ increased by $28.84 \%$ when $\mathrm{U}_{2}$ was added to ANN-MOD1.
Similarly, $\mathrm{U}_{2}$ and $\mathrm{R}_{\mathrm{s}}$ were separately added to ANN-MOD2. The $R^{2}$ increased drastically from 80.4 to $99.1 \%$, i.e., a 23.56 $\%$ increase, when $\mathrm{U}_{2}$ was added to ANN-MOD2. However, the inclusion of $\mathrm{R}_{\mathrm{s}}$ in ANN-MOD2 did not significantly increase the $R^{2}$ value (a $2.36 \%$ increase results). Furthermore, $\mathrm{R}_{\mathrm{s}}$ increased the $R^{2}$ slightly by $2.36 \%$ when it was added to ANN-MOD3. This result indicates that $R_{s}$ had an insignificant effect on $\mathrm{ET}_{\text {ref }}$ modelling. The ANN-MOD8 model 
Prediction ET using ANN

Table 4. Statistical performance of the optimized ANN models during validation, using data collected from 1980 to 2010 by six meteorological stations.

\begin{tabular}{|c|c|c|c|c|c|c|c|c|c|c|c|c|c|}
\hline \multirow[t]{2}{*}{ Model } & \multirow[t]{2}{*}{ Inputs } & \multicolumn{4}{|c|}{$h_{c 5-105}$} & \multicolumn{4}{|c|}{$\mathbf{h}_{\mathbf{c 5 0}}$} & \multicolumn{4}{|c|}{$h_{\mathrm{c} 12}$} \\
\hline & & $\overline{\mathbf{R}^{2}(\%)}$ & $\begin{array}{c}\text { OI } \\
(\%)\end{array}$ & $\begin{array}{l}\text { RMSE } \\
(\mathbf{m m} / \mathbf{d})\end{array}$ & $\begin{array}{c}\text { MAE } \\
(\mathbf{m m} / \mathbf{d})\end{array}$ & $\begin{array}{c}\mathbf{R}^{2} \\
(\%)\end{array}$ & $\begin{array}{c}\text { OI } \\
(\%)\end{array}$ & $\begin{array}{l}\text { RMSE } \\
(\mathbf{m m} / \mathbf{d})\end{array}$ & $\begin{array}{c}\text { MAE } \\
(\mathbf{m m} / \mathbf{d})\end{array}$ & $\begin{array}{c}\mathbf{R}^{2} \\
(\%)\end{array}$ & $\begin{array}{c}\text { OI } \\
(\%)\end{array}$ & $\begin{array}{l}\text { RMSE } \\
(\mathbf{m m} / \mathbf{d})\end{array}$ & $\begin{array}{c}\text { MAE } \\
(\mathbf{m m} / \mathbf{d})\end{array}$ \\
\hline ANN-MOD1 & $\mathrm{T}_{\mathrm{x}}, \mathrm{T}_{\mathrm{n}}, \mathrm{T}_{\mathrm{a}}, \mathrm{h}_{\mathrm{c}}$ & 66.6 & 79.2 & 3.19 & 2.23 & 61.2 & 76.1 & 2.87 & 2.12 & 68.4 & 76.2 & 1.84 & 1.32 \\
\hline ANN-MOD2 & $\mathrm{T}_{\mathrm{x}}, \mathrm{T}_{\mathrm{n}}, \mathrm{T}_{\mathrm{a}}, \mathrm{Rh}_{\mathrm{x}}, \mathrm{Rh}_{\mathrm{n}}, \mathrm{Rh}_{\mathrm{a}}, \mathrm{h}_{\mathrm{c}}$ & 83.1 & 87.5 & 2.41 & 1.61 & 79.1 & 85.5 & 2.17 & 1.50 & 80.4 & 81.9 & 1.58 & 1.16 \\
\hline ANN-MOD3 & $\mathrm{T}_{\mathrm{x}}, \mathrm{T}_{\mathrm{n}}, \mathrm{T}_{\mathrm{a}}, \mathrm{u}_{2}, \mathrm{~h}_{\mathrm{c}}$ & 83.9 & 89.2 & 2.22 & 1.59 & 82.8 & 87.4 & 2.01 & 1.50 & 85.1 & 89.3 & 1.17 & 0.88 \\
\hline ANN-MOD4 & $\mathrm{T}_{\mathrm{x}}, \mathrm{T}_{\mathrm{n}}, \mathrm{T}_{\mathrm{a}}, \mathrm{R}_{\mathrm{s}}, \mathrm{h}_{\mathrm{c}}$ & 66.5 & 79.9 & 3.13 & 2.19 & 62.3 & 77.1 & 2.81 & 2.08 & 73.4 & 81.0 & 1.63 & 1.14 \\
\hline ANN-MOD5 & $\mathrm{T}_{\mathrm{x}}, \mathrm{T}_{\mathrm{n}}, \mathrm{T}_{\mathrm{a}}, \mathrm{Rh}_{\mathrm{x}}, \mathrm{Rh}_{\mathrm{n}}, \mathrm{Rh}_{\mathrm{a}}, \mathrm{u}_{2}, \mathrm{~h}_{\mathrm{c}}$ & 98.9 & 98.8 & 0.56 & 0.44 & 98.4 & 98.3 & 0.59 & 0.47 & 95.6 & 94.8 & 0.77 & 0.60 \\
\hline ANN-MOD6 & $\mathrm{T}_{\mathrm{x}}, \mathrm{T}_{\mathrm{n}}, \mathrm{T}_{\mathrm{a}}, \mathrm{Rh}_{\mathrm{x}}, \mathrm{Rh}_{\mathrm{n}}, \mathrm{Rh}_{\mathrm{a}}, \mathrm{R}_{\mathrm{s}}, \mathrm{h}_{\mathrm{c}}$ & 85.1 & 88.8 & 2.27 & 1.45 & 82.2 & 87.4 & 2.01 & 1.32 & 85.2 & 85.2 & 1.41 & 1.03 \\
\hline ANN-MOD7 & $\mathrm{T}_{\mathrm{x}}, \mathrm{T}_{\mathrm{n}}, \mathrm{T}_{\mathrm{a}}, \mathrm{u}_{2}, \mathrm{R}_{\mathrm{s}}, \mathrm{h}_{\mathrm{c}}$ & 83.1 & 88.3 & 2.32 & 1.63 & 82.1 & 86.3 & 2.11 & 1.54 & 86.6 & 90.8 & 1.08 & 0.78 \\
\hline ANN-MOD8 & $\mathrm{T}_{\mathrm{x}}, \mathrm{T}_{\mathrm{n}}, \mathrm{T}_{\mathrm{a}}, \mathrm{Rh}_{\mathrm{x}}, \mathrm{Rh}_{\mathrm{n}}, \mathrm{Rh}_{\mathrm{a}}, \mathrm{u}_{2}, \mathrm{R}_{\mathrm{s}}, \mathrm{h}_{\mathrm{c}}$ & 99.8 & 99.7 & 0.21 & 0.15 & 99.8 & 99.3 & 0.29 & 0.22 & 99.4 & 98.2 & 0.38 & 0.30 \\
\hline
\end{tabular}

outperformed all of the other models on all of the performance criteria.

Spatial assessment of ANN models: The effectiveness of the ANN models can be demonstrated by estimating the $\mathrm{ET}_{\text {ref }}$ at other sites, validating the reliability and stability of these models. As mentioned previously, the validation process used three crop height values. Using $\mathrm{h}_{\mathrm{c}}=5-105 \mathrm{~cm}$ gave a maximum $\mathrm{ET}_{\text {ref }}$ value of $40 \mathrm{~mm} /$ day. The ANN models' $R^{2}$ values ranged from 66.6 to $99.8 \%$, OI values from 79.2 to $99.7 \%$, $R M S E$ values from 0.21 to $3.19 \mathrm{~mm} /$ day and $M A E$ values from 0.15 to $2.23 \mathrm{~mm} /$ day as shown in Table 4. Comparing the model performance criteria with $\mathrm{h}_{\mathrm{c}}=5-105 \mathrm{~cm}$ showed little difference between the training and validation processes. The ratio of variation in the $R^{2}$ between the training and validation processes for ANN-MOD1 (1.95\%), ANN-MOD5 $(0.20 \%)$ and ANN-MOD8 $(0.0 \%)$ indicated that these models have good network activity. In contrast, the ratio of variation in the $R^{2}$ increased slightly for ANN-MOD2 (3.48\%), ANNMOD3 (3.82\%) and ANN-MOD6 (2.93\%). The ratio increased drastically for ANN-MOD4 (8.57\%) and ANNMOD7 (6.61\%).

The ANN models were tested using $h_{c}=50 \mathrm{~cm}$ to validate their feasibility on alfalfa and $\mathrm{h}_{\mathrm{c}}=12 \mathrm{~cm}$ to validate their feasibility on grass. The maximum $\mathrm{ET}_{\text {ref }}$ was $35 \mathrm{~mm} /$ day on alfalfa and $25 \mathrm{~mm} /$ day on grass. The ANN models on alfalfa had $R^{2}$ values ranging from 61.2 to $99.8 \%, R M S E$ values from 0.29 to $2.87 \mathrm{~mm} /$ day, $O I$ values from 76.1 to $99.3 \%$ and $M A E$ values from 0.22 to $2.12 \mathrm{~mm} /$ day (Table 4 ). The ANN models on grass had $R^{2}$ values from 68.4 to $99.4 \%, R M S E$ values from 0.38 to $1.84 \mathrm{~mm} /$ day, $O I$ values from 76.2 to $98.2 \%$ and $M A E$ values from 0.30 to $1.32 \mathrm{~mm} /$ day.

The $R^{2}$ value decreased on alfalfa for ANN-MOD1 (11.76\%), ANN-MOD2 (1.64\%), ANN-MOD3 (2.77\%), ANN-MOD4 (17.81\%), ANN-MOD6 (3.64\%) and ANN-MOD7 (5.48\%), indicating that these models performed better on grass than on alfalfa (Table 4). However, the $R^{2}$ value decreased on grass for ANN-MOD5 (2.84\%) and ANN-MOD8 (0.40\%), indicating that these models performed slightly better on alfalfa than on grass.

ANN vs. PMFAO and PMASCE: In both cases grass and alfalfa, a comparison between the best models has been made which is ANN-MOD8. The 1:1 line in Figure 7 shows the $\mathrm{ET}_{\text {ref }}$ values predicted by the data driven models and the observed values (PMFAO and PMASCE), using the data set collected by six stations from 1980 to 2010 (not used in the training and testing process).
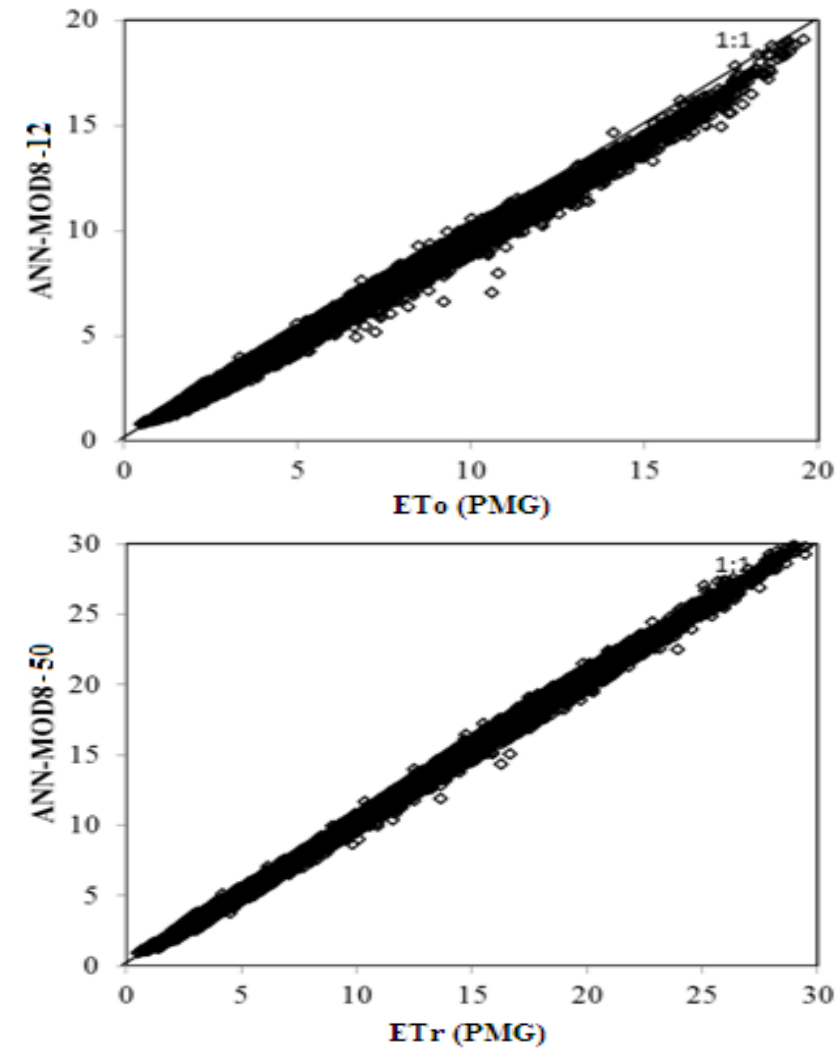

Figure 7. Comparison of the alfalfa $\left(E T_{r}\right)$ and grass $\left(E T_{0}\right)$

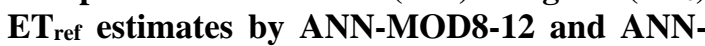
MOD8-50, and the values from the PMG equation.

The figure shows that ANN-MOD8 on basis of grass (ANNMOD8-12) had higher deviation compared to ANN-MOD8 on basis of alfalfa (ANN-MOD8-50), implying that it caused 
Yassin, Alazba \& Mattar

Table 5. Statistical performance of ANN-MOD8-50 and ANN-MOD8-12 using data collected from 1980 to 2010 by six meteorological stations.

\begin{tabular}{lcccc}
\hline Models & $\left.\mathbf{R}^{\mathbf{2}} \mathbf{\%}\right)$ & OI $(\boldsymbol{\%})$ & RMSE $(\mathbf{m m} / \mathbf{d})$ & MAE $(\mathbf{m m} / \mathbf{d})$ \\
\hline ANN-MOD8-50 & 99.8 & 0.991 & 0.29 & 0.22 \\
ANN-MOD8-12 & 99.4 & 0.982 & 0.38 & 0.30 \\
\hline
\end{tabular}

greater underestimation. Table 5 shows that ANN-MOD8-50 performed better than ANN-MOD8-12 with lower error measure values and higher correlation coefficients. The $R^{2}$ and $O I$ for ANN-MOD8-50 had also 0.4\% and 0.9\% more accurate than that from the ANN-MOD8-12. The ANNMOD8-50 had a $2.4 \%$ and $2.7 \%$ decrease in the RMSE and MAE under ANN-MOD8-12, receptivity.

Conclusions: Eight ANN models were developed to estimate the daily $\mathrm{ET}_{\text {ref }}$ under arid and hyper arid conditions. The climatic data were collected from 19 meteorological stations covering the period of 1980 to 2010 . While data obtained from the 13 metrological stations were used to develop the ANN models, the data from the other six stations were used for spatial validation of the eight developed ANN models. The best performed ANN model, i.e. ANN-MOD8, was that included all climatic parameters in comparison with PM model. On the other hand, the ANN model with the temperature as the only input climatic parameter performed the least. Compared to PM model, the ANN-MOD8 with its simple algebraic equation can perfectly predict $\mathrm{ET}_{\text {ref }}$ for a wide range of hc varying from $5 \mathrm{~cm}$ to $105 \mathrm{~cm}$. An interesting result of the current study revealed that the ANN-MOD5, ANN model with no Rs, can compete with ANN-MOD8 considered the most accurate model to predict the daily $\mathrm{ET}_{\text {ref }}$ under the hyper arid environment. This inserting outcome leads to a possible conclusion that the climatic parameter $\mathrm{U}_{2}$ is more important than Rs under the circumstances of this study. Furthermore, it is observed that ANN model consisting of all the input parameters with $h_{c}=50 \mathrm{~cm}$ was found to perform better than with $h_{c}=12 \mathrm{~cm}$. Therefore, the ANN technique can be very helpful when applying in irrigation scheduling and management of agriculture water resources.

Acknowledgments: The project was financially supported by King Saud University, Vice Deanship of Research Chairs. Moreover, the climatic data used in this study were obtained from the Presidency of Meteorology and Environment (PME), Kingdom of Saudi Arabia. The authors highly appreciate this effort and would like thank PME for continues collaboration of providing the data.

\section{REFERENCES}

Alazba, A.A. 2004. Estimating palm water requirements using Penman-Monteith mathematical model. J. King Saud Univ. 16:137-152.

Ali, M.H. 2010. Fundamentals of Irrigation and On-farm
Water Management, Vol. 1. Springer Science, Business Media, LLC.

Allen, R.G., L.S. Pereira, D. Raes and M. Smith. 1998. Crop evapotranspiration guidelines for computing crop water requirements. FAO Irrigation and Drainage, Paper No. 56, Food and Agriculture Organization of the United Nations, Rome.

ASCE-EWRI. 2005. The ASCE standardized reference evapotranspiration equation. Environmental and Water Resources, Institute of the American Society of Civil Engineers Task Committee on Standardization of Reference Evapotranspiration Calculation, Washington, DC, USA, p.70.

Chattopadhyay, S., R. Jain and G. Chattopadhyay. 2009. Estimating potential evapotranspiration from limited weather data over Gangetic West Bengal, India: a neurocomputing approach. Meteorol. Appl. 16:403-411.

Chiew, F.H.S., N.N. Kamaladassa, H.M. Malano and T.A. McMahon. 1995. Penman-Monteith, FAO-24 reference crop evapotranspiration and class-A pan data in Australia. Agric. Water Manage. 28:9-21.

Dai, X., H. Shi, Y. Li, Z. Ouyang and Z. Huo. 2009. Artificial neural network models for estimating regional reference evapotranspiration based on climate factors. Hydrol. Process. 23:442-450.

Dawson, W.C. and R. Wilby. 1998. An artificial neural networks approach to rainfall-runoff modeling. Hydrol. Sci. J. 43:47-66.

De Souza, F. and R.E. Yoder. 1994. ET estimation in the north east of Brazil: Hargreaves or Penman-Monteith equation. Proc. Technical Paper ASAE International Winter Meeting, American Society of Agricultural Engineers, St. Joseph, Mich.

Fangmeier, D.D., W.J. Elliot, S.R. Workman, R.L. Huffman and G.O. Schwab. 2006. Soil and Water Conservation Engineering, $5^{\text {th }}$ Ed. United States: THOMSON.

Fisher, J.B., A. Terry, A. DeBiase, Y. Qi1, M. Xu and H. Allen. 2005. Evapotranspiration models compared on a Sierra Nevada forest ecosystem. Environ. Model. Softw. 20:783-796.

Fooladmand, H.R. and M. Haghighat. 2007. Spatial and temporal calibration of Hargreaves equation for calculating monthly ETo based on Penman-Monteith method. Irrig. Drain. 56:439-449.

Fooladmand, H.R., H. Zandilak and M.H. Ravanan. 2008. Comparison of different types of Hargreaves equation for estimating monthly evapotranspiration in the south of Iran. Arch. Agron. Soil Sci. 54:321-330. 
Gavilan, P., J. Berengena and R.G. Allen. 2007. Measuring versus estimating net radiation and soil heat flux: Impact on Penman-Monteith reference ET estimates in semiarid regions. Agric. Water Manage. 89:275-286.

Gavilan, P., I.J. Lorite, S. Tornero and J. Berengena. 2006. Regional calibration of Hargreaves equation for estimating reference ET in a semiarid environment. Agric. Water Manage. 81:257-281.

George, B.A., B.R.S. Reddy, N.S. Raghuwanshi and W.W. Wallender. 2002. Decision support system for estimating reference evapotranspiration. J. Irrig. Drain. Eng-ASCE 128:1-10.

Gocic, M. and S. Trajkovic. 2010. Software for estimating reference evapotranspiration using limited weather data. Comput. Electron. Agric.71:158-162.

Gorka, L., O.B. Amais and J.L. Jose. 2008. Comparison of artificial neural network models and empirical and semiempirical equations for daily reference evapotranspiration estimation in the Basque County (Northern Spain). Agric. Water Manage. 95:553-565.

Haykin, S. 1999. Neural networks. A comprehensive foundation. Prentice Hall International Inc., New Jersey.

Huo, Z., S. Feng, S. Kang and X. Dai. 2012. Artificial neural network models for reference evapotranspiration in an arid area of northwest China. J. Arid Environ. 82:81-90.

Hupet, F. and M. Vanclooster. 2001. Effect of the sampling frequency of meteorological variables on the estimation of the reference evapotranspiration. J. Hydrol. 243:192204.

Irmak, S., A. Irmak, R.G. Allen and J.W. Jones. 2003. Solar and net radiation based equations to estimate reference evapotranspiration in humid climates. J. Irrig. Drain. Eng. 129:336-347.

Izadifar, Z. 2010. Modeling and analysis of actual evapotranspiration using data driven and Wavelet techniques. Master Thesis, University of Saskatchewan, Saskatoon, Saskatchewan, Canada.

Jain, S.K., P.C. Nayak and K.P. Sudhir. 2008. Models for estimating evapotranspiration using artificial neural networks, and their physical interpretation. Hydrol. Process. 22:2225-2234.

Jensen, M.E., R.D. Burman and R.G. Allen. 1990. Evapotranspiration and irrigation water requirements. ASCE Manuals and Reports on Engineering Practices No. 70., Am. Soc. Civil Engrs., New York, NY, p.360.

Kişi, O. 2006. Generalized regression neural networks for evapotranspiration modeling. Hydrol. Sci. J. 51:10921105.

Kişi, O. 2007. Evapotranspiration modeling from climatic data using aneural computing technique. Hydrol. Process. 21:1925-1934.

Kişi, O. and O. Oztürk. 2007. Adaptive neuro-fuzzy computing technique for evapotranspiration estimation. J. Irrig. Drain. Engr. 133:68-379.
Kumar, M., A. Bandyopadhyay, N.S. Rahguwanshi and R. Singh. 2008. Comparative study of conventional and artificial neural network based reference evapotranspiration estimation models. Irrig. Sci. 26:531545.

Kumar, M., N.S. Raghuwanshi and R. Singh. 2011. Artificial neural networks approach in evapotranspiration modeling: a review. Irrig. Sci.29:11-25.

Kumar, M., N.S. Raghuwanshi, R. Singh, W.W. Wallender and W.O. Pruitt. 2002. Estimating evapotranspiration using artificial neural network. J. Irrig. Drain. Engr. 128:224-233.

Landeras, G., A.O. Barredo and J.J. Lopez. 2008. Comparison of artificial neural network models and empirical and semi-empirical equations for daily reference evapotranspiration estimation in the Basque Country (Northern Spain). Agric. Water Manage. 95:553-565.

Li, F.Z. and A. Beswick. 2005. Sensitivity of the FAO-56 crop reference evapotranspiration to different input data. Technical report. Queensland Government, Natural Resources and Mines; pp.1-14.

Monteith, J.L. 1965. The state and movement of water in living organisms. In Proceedings, Evaporation and Environment, XIXth Symp., Soc. For Exp. Biol., Swansea. Cambridge Univ. Press: New York, pp.205234.

Monteith, J.L. 1973. Principles of Environmental Physics. Edward Arnold: London.

Naoum, S. and K.I. Tsanis. 2003. Hydroinformatics in evapotranspiration estimation. Environ. Model. Softw. 18:261-271.

Sabziparvar, A.A. and H. Tabari. 2010. Regional estimation of reference evapotranspiration in arid and semiarid regions. J. Irrig. Drain. Eng-ASCE 136:724-731.

Saudi Geological Survey. 2012. King Saudi Arabia: Facts and Numbers, Ed 1.

Smith, M., R.G. Allen, J.L. Monteith, L.S. Pereira, A. Perrier and W.O. Pruitt. 1991. Report on the Expert Consultation on Revision of FAO Guidelines for Crop Water Requirements, Land and Water Development Division, FAO, Rome.

Sudheer, K.P., A.K. Gosain and K.S. Ramasastri. 2003. Estimating actual evapotranspiration from limited climatic data using neural computing technique. J. Irrig. Drain. Eng-ASCE. 129:214-218.

Tabari, H. 2010. Evaluation of reference crop evapotranspiration equations in various climates. Water Resour. Manage. 24:2311-2337.

Tabari, H. and P. Talaee. 2011. Local calibration of the Hargreaves and Priestley-Taylor equations for estimating reference evapotranspiration in arid and cold climates of Iran based on the Penman-Monteith model. J. Hydrol. Eng. 16:837-845.

Temesgen, B., S. Eching, B. Davidoff and K. Frame. 2005. 
Comparison of some reference evapotranspiration equations for California. J. Irrig. Drain. Eng-ASCE 1311:73-84.

Trajkovic, S. 2005. Temperature-based approaches for estimating reference evapotranspiration. J. Irrig. Drain. Eng-ASCE 131:316-323.

Traore, S., Y-M. Wang and T. Kerh. 2010. Artificial neural network for modeling reference evapotranspiration complex process in Sudano-Sahelian zone. Agric. Water Manage. 97:707-714.

Walter, I.A., R.G. Allen, R. Elliott, D. Itenfisu, P. Brown, M.E. Jensen, B. Mecham, T.A. Howell, R. Snyder, S. Echings, T. Spofford, M. Hattendorf, D. Martin, R.H. Cuenca and J.L. Wright. 2001. The ASCE standardized reference evapotranspiration equation. Environmental and Water Resources Institute (EWRI) of the ASCE.

Xiaoying, L., L. Erda. 2005. Performance of the Priestley-
Taylor equation in the semi-arid climate of North China. Agric. Water Manage. 71:1-17.

Xu, C.Y. and V.P. Singh. 2001. Evaluation and generalization of temperature based equations for calculating evaporation. Hydrol. Process. 15:305-319.

Xu, C.Y. and V.P. Singh. 2002. Cross comparison of empirical equations for calculating potential evapotranspiration with data from Switzerland. Water Resour. Manag. 16:197-219.

Yin, Y., S. Wu, D. Zheng and Q. Yang. 2008. Radiation calibration of FAO56 Penman-Monteith model to estimate reference crop evapotranspiration in China. Agric. Water Manage. 95:77-84.

Zanetti, S.S., E.F. Sousa, V.P.S. Oliveira, F.T. Almeida and S. Bernardo. 2007. Estimating evapotranspiration using artificial neural network and minimum climatological data. J. Irrig. Drain. Eng-ASCE 133:83-89. 